\title{
APLICAÇÃO FOLIAR DE MICRONUTRIENTES EM CITROS
}

\author{
CARLOS SÉRGIO TIRITAN \\ Engenheiro Agrônomo
}

Orientador: Prof. Dr. Antonio Enedi Boaretto

Dissertação apresentada à Escola Superior de Agricultura "Luiz de Queiroz", da Universidade de São Paulo, para obtenção do título de Mestre em Agronomia, Área de Concentração Solos e Nutrição de Plantas.

\section{PIRACICABA}

Estado de São Paulo - Brasil

Maio -1996 
Dados Intemacionais de Catalogação'na Publicação (CIP) DIVISÃO DE BIBLIOTECA E DOCUMENTAÇÃOO - Campus ${ }^{11}$ Luiz de Queiroz"/USP

Tiritan, C.irlos Sérgio

Aplicacação foliar de micronutrientes em cítros / Carlos Sérgio Tirltan. - Piracicaba, 1996.

64 p.: il.

Dissertação (mestrado) - - Escofà Superior de :A.gricultura Luiz de Qtleiroz, 1996.

Bibliografia.

t. Adubação foliar 2. Laranja - Adubação foliar 3. Micronutriente em laranja Aplicação - Efeito 1 Título

CDD 631.8

634.31 


\section{APLICAÇÃO FOLIAR DE MICRONUTRIENTES EM CITROS}

\section{CARLOS SÉRGIO TIRITAN}

Aprovada em: 23.08.1996

Comissão Julgadora:

Prof. Dr. Antonio Enedi Boaretto

Prof. Dr. Francisco Maximino Fernandes

FEIS/UNESP

Prof. Dr. Francisco de Assis A Mourão Filho

ESALQ/USP

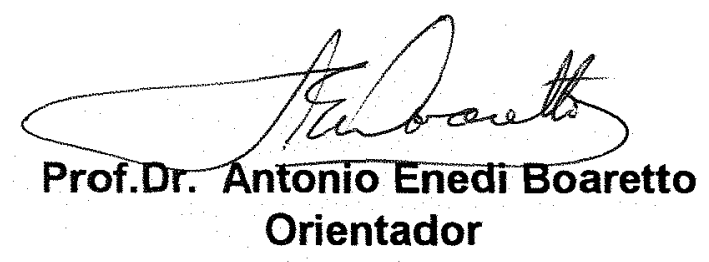


Aos meus irmãos:

João, Fátima, Célia, Mário, Beth e Odair

Pelo apoio, amizade, companherismo e amor

\section{OFEREÇO}

Aos meus pais

Augusto Tiritan \& Ana Alves Tiritan

Pelo exemplo de vida com simplicidade, honestidade, humildade, dedicação e amor

Minha eterna admiração

DEDICO 


\section{AGRADECIMENTOS}

\section{A todos que direta ou indiretamente contribuiram para a realização do presente trabalho, externo meus sinceros agradecimentos, em especial:}

- A Escola Superior de Agricultura "Luiz de Queiroz". (ESALQ/USP)

- A Faculdade de Engenharia de Ilha Solteira (FEIS/UNESP)

- Ao CNPq pela bolsa cedida durante o curso.

- A Empresa Ajinomoto.

- A Universidade Oeste Paulista (Presidente Prudente).

- Ao Prof. Dr. Antonio Enedi Boaretto,pela orientação.

- Ao Prof. Luis Ignácio Prochnow e ao Prof. Dr. Takashi Muraoka.

- Ao Prof.Dr. Geraldo Victorino de França, ex-coordenador do Curso de Pós-Graduação em Solos e Nutrição de Plantas, pelo tratamento dispensado durante o curso de PósGraduação.

- Aos técnicos de laboratório: Marileuza A.B. Elias, Sandra T.Pereira, João O.Salvador.

- A Amiga Henriqueta M.G.Fernandes pela colaboração na realização deste trabalho.

- A Amiga Maria Aparecida Calegaro, pela companhia e ajuda durante a redação final deste trabalho.

- Aos Colegas de Pós-Graduação: Fernando Carvalho Oliveira; Claudio Roberto Marciano; José Antonio da Silva; Regis; Vanderley; Reynaldo; Luciana; Elen; Hila; Walkyria.

- Aos demais companheiros de curso. 


\section{SUMÁRIO}

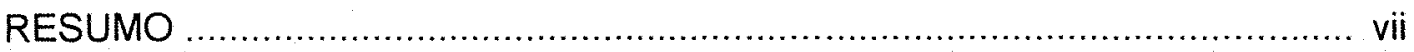

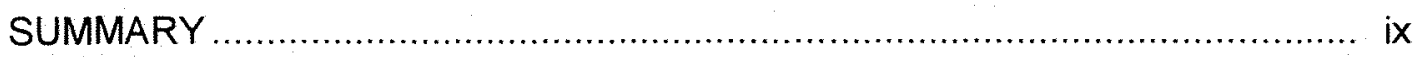

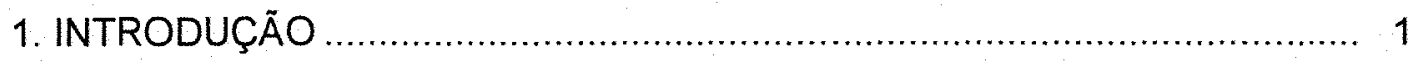

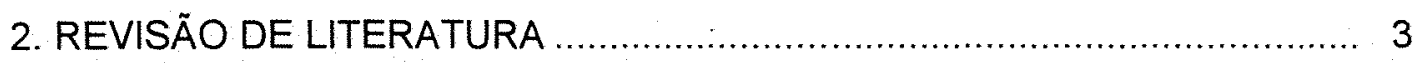

2.1. Generalidades Sobre Adubação Foliar................................. 3

2.2. Adubação Foliar com Zinco ............................................. 4

2.3. Adubação Foliar com Manganês ........................................ 9

2.4. Adubação Foliar com Boro ................................................. 11

2.5. Adubação Foliar com Produtos Biológicos ............................ 13

2.6. Adubação Foliar e sua Influência no Solo ............................. 17

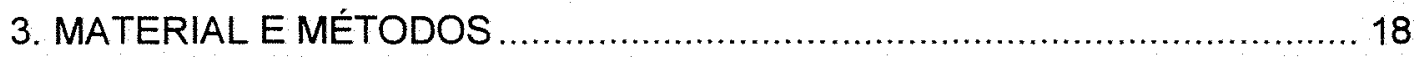

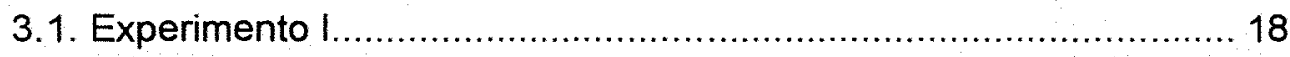

3.1.1. Local.................................................................. 18

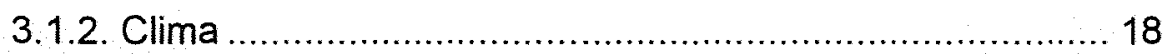

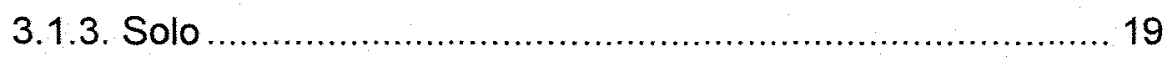

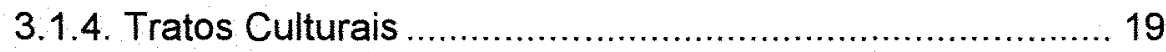

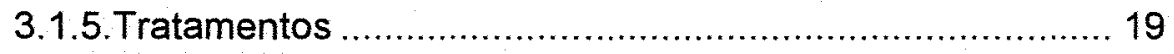

3.1.6. Aplicações ......................................................... 25

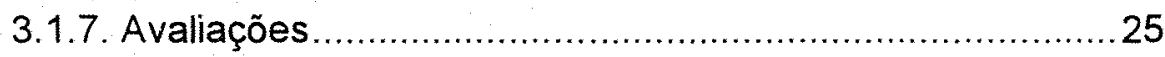


3.1.7.1. Amostragens de Folhas e Análise Foliar........... 25

3.1.7.2 Colheita e Análise de Frutos ...................... 26

3.1.8. Tratamento Estatístico dos Resultados Obtidos............. 27

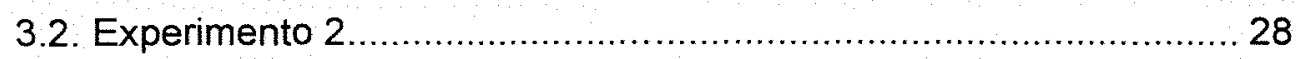

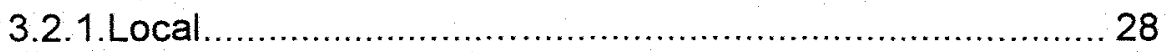

3.2.2. Idades dos Pomares............................................ 28

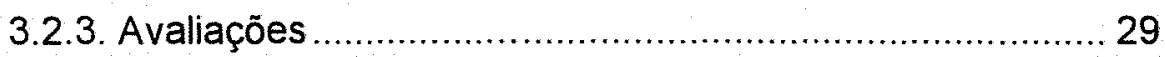

3.2.3.1. Diagnose Foliar ..................................... 29

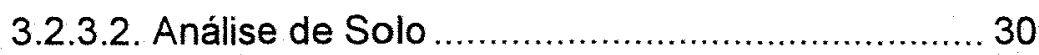

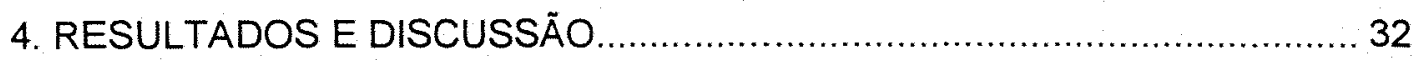

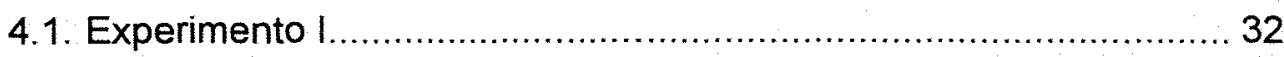

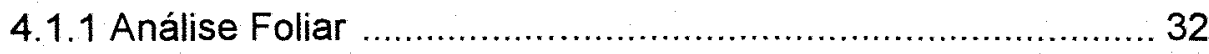

4.2. Produção e Análises Tecnológica dos Frutos............................. 39

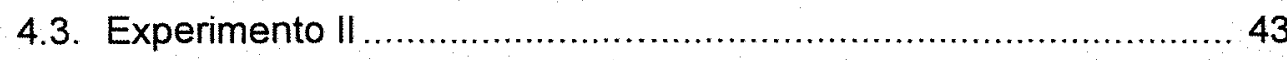

4.3.1 Resultados das Análises de Folhas ........................... 43

4.3.2. Resultados da Análise do Solo para Micronutrientes ........ 44

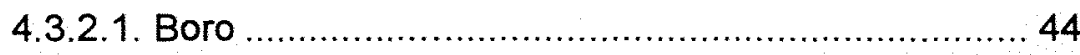

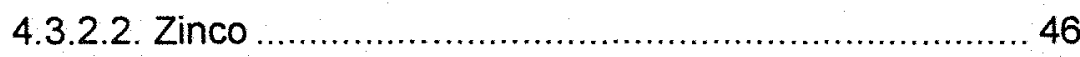

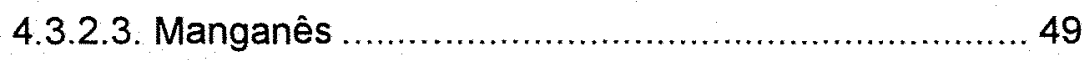

4.3.2.4. Cobre ..................................................... 51

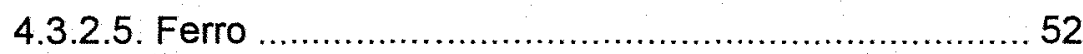

4.4. Discussão Geral dos Micronutrientes ..................................... 54

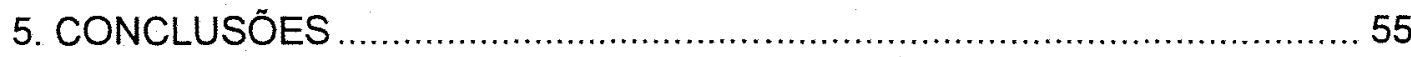

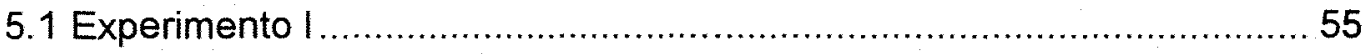

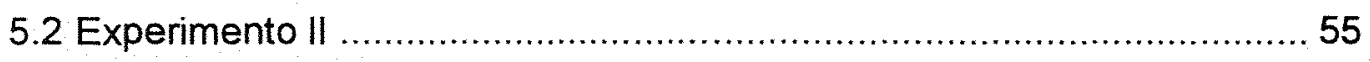

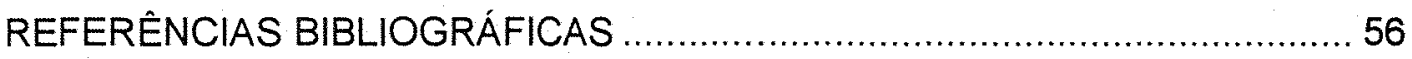




\title{
APLICAÇÃO FOLIAR DE MICRONUTRIENTES EM CITRUS
}

\author{
Autor: Carlos Sérgio Tiritan \\ Orientador:Antonio Enedi Boaretto
}

\section{RESUMO}

O trabalho desenvolvido em duas etapas, constituiu-se de dois experimentos. $O$ primeiro experimento foi conduzido em um pomar com laranjeiras de 8 anos, variedade Pera (Citrus simensis, L. Osbeck) enxertada sobre limoeiro cravo ( Citrus limonia, L. Osbeck). A finalidade do experimento foi estudar a utilização de micronutrientes (principalmente $B, M n$ e $Z n$ ) em diferentes formas: sais quelatos e resíduos agro-industriais contendo além de micronutrientes outros compostos orgânicos como, vitaminas, aminoácidos, etc.

O experimento constou de 9 tratamentos: testemunha, produto comercial nas dosagens de $\left(4,8,12,16,20\right.$ e $\left.24 \quad L h^{-1}\right)$, aplicação da recomendação técnica do Grupo Paulista de Adubação e Calagem para Citrus, (1994) e tratamento baeseado no resultado da diagnose foliar, neste tratamento só foi feito a aplicação foliar se o teor foliar do nutriente estivesse abaixo do nível adequado estabelecido pelo Grupo Paulista de Adubação e Calagem para Citrus, (1994). O delineamento estatístico utilizado foi de blocos casualizados com 6 repetições e 20 plantas por parcela e 6 plantas centrais, consideradas úteis. $O$ experimento foi conduzido por 2 anos, sendo que em cada ano fez-se 2 pulverizações foliares e 2 análises químicas de folha, sempre um mês após a pulverização. No final de cada ano fez-se a colheita dos frutos, e determinou-se o diâmetro dos frutos, peso médio dos frutos. $E$ nos frutos realizou-se a análise tecnológica. 
A análise e interpretação dos resultados permitiram as seguintes conclusões:

1- $A$ aplicação de $B, M n$ e $Z n$, via foliar elevou os teores destes nas folhas;

2- Os teores de boro, zinco e manganês apresentaram diferenças estatísticas entre as doses do produto comercial e em relação ao tratamento testemunha; 3- Não houve efeito da adubação foliar no teor dos macronutrientes, nos 2 anos de estudos;

4- A aplicação dos micronutrientes não tiveram influência na produção, diâmetro médio dos frutos e parâmetros tecnológicos, nos dois anos de estudos.

No segundo experimento estudou-se o acúmulo de micronutrientes ( $B, M n$ e $\mathrm{Zn}$ ) no solo, em função das pulverizações foliares. $O$ experimento foi conduzido em um pomar com plantas de laranja (variedade Pera enxertada sobre limoeiro Cravo e variedade Natal enxertada sobre tangerina Cleopatra) com idades variando entre 3 a 20 anos e uma área de testemunha sem plantas de laranja. Foram coletadas amostras de solo em 3 posições distintas: próximo ao colo da planta, projeção da copa e na entrelinha das plantas a uma profundidade de $10 \mathrm{~cm}$.

A análise e a interpretação dos resultados permitiram as seguintes conclusões:

a- A adubação foliar interfere muito pouco nos teores de micronutrientes no solo, em função da idade do pomar;.

b- Para todos os micronutrientes estudados ( $\mathrm{B}, \mathrm{Mn}, \mathrm{Cu}, \mathrm{Fe}$ e $\mathrm{Zn}$ ), houve uma tendência de aumento dos teores no solo, para as posições, projeção da copa e próximo ao colo da planta, em relação a entre-linha. 


\title{
CITRUS FOLIAR MICRONUTRIENT APPLICATION
}

\author{
Author: Carlos Sérgio Tiritan \\ Adviser: Prof. Dr. Antonio Enedi Boaretto
}

\section{SUMMARY}

The purpose of this research was to study and verify the technical viability of micronutrients utilization $(B, M n$ and $Z n)$ in different ways; chelating salts and agro-industrials waste containing these substances and other organic compounds, like vitamins, aminoacids, etc.

The work was developed in two steps, constituted by two experiments.

The first one was conducted in a eight year old orange orchard, 'Pera (Citrus sinensis, L. Osbeck) grafted on "Rangpur Lime (Citrus limonia, L. Osbeck).

The experiment consisted of the micronutrient applications of Ajifol $^{\mathrm{TM}}$, based on technical recommendation through foliar diagnosis, at the rates of $0,4,8,12,16,20$, and $24 \mathrm{~L} \mathrm{ha}^{-1}$. The experimental design was random blocks with 6 replications, with 20 plants per plot and 6 central useful plants. The experiment took two years, in which 2 pulverization's were done per year and foliar analysis one month after pulverization. At the end of each year fruits were harvested and the yield, fruit diameter, average of fruit weight and technological analyses were recorded.

The conclusions based on data analysis and interpretation were:

1 - There was increase in micronutrients contents with foliar application, irrespective to the application way, showing statistical differences in relation to control.

2 - There were statistical differences between different doses of Ajifol ${ }^{\mathrm{TM}}$ in relation to the control, for boron, manganese and zinc; 
3 - There were no statistical differences for macronutrients in two year period and 4 - The micronutrient application was not sufficient to increase the yield average fruit diameter and technological parameters in two year period.

The objective of second experiment was to verify the micronutrient accumulation on soil ( $B, M n$ and $Z n$ ) caused by foliar applications. It was conducted in an orange farm with very uniform soil, climate and crops management, with three to twenty years old 'Pera' orange grafted on 'Rangpur lime and 'Natal' orange grafted on 'Cleopatra' tangerine (Citrus sinensis, L. Osbeck), and an area without orange trees. Soil samples were taken for analysis in three different positions: near the "stem", foliage projection and between plants line, $10 \mathrm{~cm}$ bellow the surface.

The conclusions based on data analysis and interpretation were:

1 - There were statistical differences related with micronutrients levels between plants of different ages and sampling position and

2 - For all micronutrients studied ( $\mathrm{B}, \mathrm{Mn}, \mathrm{Cu}, \mathrm{Fe}$ and $\mathrm{Zn}$ ) there was an increase for sampling positions near "stem" and under foliage, compared with inter lines. 


\section{INTRODUÇÃo}

A adubação é uma prática agrícola necessária quando o solo não pode fornecer os nutrientes que a cultura necessita, para apresentar alta produtividade e garantir retorno econômico satisfatório. Quando se trata de micronutrientes, a aplicação foliar entra como uma forma bastante usada para fornecer estes nutrientes, principalmente em culturas perenes.

O fornecimento de micronutrientes diretamente às folhas é utilizado na complementação da adubação mineral de macronutrientes via solo. A eficácia desta prática é atribuída à rápida absorção dos nutrientes pelas plantas. No entanto, existem alguns empecilhos que limitam o seu uso em larga escala, tais como:, as soluções são de baixas concentrações, incompatibilidade dos adubos com defensivos, equipamentos inadequados, etc (Franke,1986). Além disso há necessidade de nível tecnológico mais avançado dos agricultores e que produtos sejam de fato eficientes. Esses problemas portanto limitam a prática da adubação foliar, ficando ela mais restrita aos micronutrientes.

Nos pomares citrícolas é rotineira a aplicação de micronutrientes diretamente às suas folhas, conjuntamente com defensivos, porque a aplicação destes no solo tem baixa eficiência (Grupo Paulista de Adubação e Calagem para Citros, 1994). Há no comércio vários produtos que podem ser empregados na adubação foliar. Nos produtos mais recentes, também são adicionadas às 
misturas, aminoácidos e vitaminas, geralmente proveniente de resíduos de indústrias de alimentos.

Diante deste fato, o primeiro objetivo é verificar o efeito de doses de um desses produtos nos teores foliares de micronutrientes, na produção e na qualidade dos frutos de laranja, tendo como comparação as quantidades de micronutrientes que são recomendadas pelos institutos de pesquisas.

Um outro aspecto relacionado a adubação foliar com micronutrientes é que grande parte da solução aplicada sobre as folhas caem ao solo. Assim o segundo objetivo é verificar o efeito da adubação foliar sobre as concentrações de boro, zinco, manganês, ferro e cobre do solo. A hipótese testada neste caso é que quanto mais velho o pomar maior é o teor destes micronutrientes no solo, e que os teores deveriam ser maiores no solo abaixo da planta do que na entrelinha. 


\section{REVISÃo DE LITERATURA}

\subsection{Generalidades Sobre Adubação Foliar}

A adubação foliar é uma prática antiga, usada na Europa desde o século passado, quando se aplicavam sobre as plantas um líquido que era obtido de esterqueiras, (Malavolta 1980). Outras referências sobre a utilização prática da adubação foliar, para correção de carências nutricionais, são apresentadas por Franke (1986).

Camargo \& Silva (1975) citam a adubação foliar e caulinar em plantas jovens, como forma de fornecer os nutrientes às plantas.

A partir da utilização do sulfato ferroso, para resolver problemas de deficiência no abacaxi no Hawai em 1915, é que levou a popularização da prática da adubação foliar nos Estados Unidos. Houve ainda grande incremento, a partir de 1940 , no uso da adubação foliar, quando verificou-se que havia possibilidade de sua utilização conjuntamente com defensivos agrícolas (Franke 1986).

Malavolta (1980) recomenda o uso da adubação foliar em citros nos seguintes casos: como forma suplementar à adubação de solo no caso dos nutrientes requeridos em grandes quantidades $(N, P, K, S, C a, M g)$. O outro caso é para o fornecimento dos nutrientes requeridos em pequenas quantidades $\left(\mathrm{g} \mathrm{ha}^{-1}\right)$, os micronutrientes, por não ser necessário repetir a operações muitas vezes. 
Segundo Hsu (1986a) a adubação foliar tem sido recomendada para corrigir deficiências nutricionais, fornecer nutrientes às plantas nas primeiras épocas de crescimento e na formação de frutos e sementes.

Para Stoller (1989) a adubação foliar com Mn, Zn, e Cu justifica-se pelo fato deles serem exigidos em pequenas quantidades pelas plantas, podendo ser fornecidos totalmente pela adubação foliar. Vale salientar que estes nutrientes têm seu aproveitamento pela cultura reduzido na aplicação via solo, pois ocorrem reações que os tornam menos disponiveis as plantas.

Segundo o grupo Paulista de Adubação e Calagem para Citros (1994) os micronutrientes mais deficientes na citricultura paulista são o zinco, o boro e o manganês, sendo que o fornecimento de zinco e manganês por meio de adubações foliares tem sido eficaz, e para boro a aplicação no solo é mais eficiente que em pulverizações foliares. Ainda segundo o Grupo Paulista de Recomendação e Calagem para Citros (1994), a época mais adequada para fazer a adubação foliar com micronutrientes é o período de vegetação das plantas. Nos pomares em formação recomenda-se de 3 a 4 aplicações. Nestes em produção, duas aplicações: a primeira na época do florescimento, logo após a queda das pétalas, aproveitando o tratamento fitossanitário e a segunda durante o fluxo de vegetação, que normalmente ocorre em janeiro-fevereiro.

\subsection{Adubação Foliar com Zinco}

Nos pomares citrícolas brasileiros, a deficiência de zinco é um problema sério e vem se agravando ano a ano nos pomares paulistas. A forma mais comum de correção utilizada pelos citricultores, é a pulverização na primavera, com sulfato de zinco comercial, na concentração $350 \mathrm{~g}$ em 100 litros de 
água (Camargo \& Silva 1975). As quantidades de zinco contida nos produtos usados no controle fitossanitário não são suficientes para o suprimento de zinco às plantas. Cita-se, como exemplo disso, o Zineb, que é usado no controle do ácaro da ferrugem, pois ele proporciona zinco às plantas apenas na proporção da sétima parte do que é necessário para a correção da deficiência do elemento (Rodrigues 1980).

Ben David (1975) descreveu, em seu trabalho, os sintomas característicos de deficiência de zinco. Aparecem manchas cloróticas nas folhas novas e morte dos brotos novos. A produção de frutos pode decrescer, e são pequenos e em caso de deficiência severa, os frutos podem até não aparecer.

Segundo Camargo \& Silva (1975) os sintomas mais visíveis da carência de zinco são: a redução do tamanho das folhas novas que se tornam amarelo avermelhadas ou de amarelo vivo até a marfim, com as nervuras permanecendo com coloração verde escura.

Para o controle da deficiência de zinco em citros existem, desde há muitos anos, inúmeros trabalhos citando a importância da adubação foliar corretiva.

Camp \& Fudge (1939) relatam que o tratamento comumente usado na Flórida é a pulverização de sulfato de zinco neutralizado com cal hidratada, enquanto na Califórnia pulveriza-se com sulfato de zinco e cal ou cinza de soda com óxido de zinco.

Instituto Interamericano de La Potassa (1958) e Malavolta et al. (1974) relatam que as carências de zinco são controladas mediante pulverizações com $300-500 \mathrm{~g}$ de sulfato de zinco e $150-250 \mathrm{~g}$ de cal em 100 litros de água. As pulverizações devem ser feitas na primavera, pois a absorção é 
maior. Nunca realizar durante o repouso vegetativo quando a absorção é muito baixa.

Chapmam (1966) relata que vários tipos de aplicações de zinco em citros já foram testadas, desde a aplicação de solução contendo zinco diretamente nas células das plantas até a introdução na planta de pregos revestido com zinco, ficando o sucesso dependente da cultura, do solo e do clima. Em geral as pulverizações com solução de sulfato de zinco adicionada com cal ou cinza de soda na metade da dosagem do sulfato de zinco são as mais usadas.

Ben David (1975) preconiza que a deficiência de zinco pode ser controlada com aplicações de sulfato de zinco no solo, quando o seu pH é baixo. Relata também, que o efeito da pulverização foliar, que é a prática mais comum de controle da deficiência de zinco, depende do composto, do teor do metal, pureza, solubilidade e granulometria dos produtos utilizados.

Labanauskas \& Puffer (1964) aplicaram sulfato de zinco via foliar e observaram que o zinco foi translocado em pequenas quantidades das folhas adubadas para as folhas mais novas. A concentração de zinco nas folhas pulverizadas foi incrementada, mas não houve aumento significativo na produção e no peso da matéria seca das folhas. Resultados semelhantes foram encontrados por Razeto \& Salas (1986), que verificaram altos teores de zinco na vegetação que recebeu a adubação foliar (na mesma estação de crescimento), o que não foi confirmada nas folhas que cresceram na vegetação da estação de crescimento seguinte.

Labanauskas et al. (1969), aplicando zinco e manganês via foliar, obtiveram aumento nos teores de zinco e manganês nas folhas novas colhidas, um ano após a aplicação. Entretanto, a presença de sulfato de manganês nas misturas reduziu os teores de zinco, e as aplicações de sulfato de zinco elevaram 
os teores de manganês e sódio nas folhas pulverizadas e reduziu os teores de nitrogênio, cálcio, magnésio e cobre.

Com o objetivo de encontrar a dose adequada, que não provoca injúria à planta, Kotur (1984), aplicou via foliar em citros, óxido de zinco nas concentrações de 0,$1 ; 0,2 ; 0,3 ; 0,4 ;$ e $0,5 \%$ e sulfato de zinco a 0,$1 ; 0,2 ; 0,3 ; 0,4$ e $0,5 \%$ e solução de sulfato de zinco neutralizado com cal hidratada, nas concentrações de 0,$1 ; 0,4 ; 0,6 ; 0,8 ;$ e $1 \%$. Semanas após a aplicação dos produtos, foi observado que as concentrações de $0,3 \%$ de óxido e $0,4 \%$ de sulfato de zinco já provocavam injúrias nas folhas. O óxido de zinco foi o mais eficiente em corrigir os sintomas de deficiência de zinco e o sulfato de zinco foi menos eficiente. Indicou o autor que óxido de zinco a $0,1 \%$ e o sulfato de zinco a $0,2 \%$ são as concentrações mais adequadas para substituir o uso convencional do sulfato de zinco neutralizado com cal hidratada, por serem mais fáceis de prepararem e mais econômicos.

Caetano (1982) estudando a adubação foliar em citros, aplicou boro, manganês e zinco nas concentrações de: $250 \mathrm{~g}$ de sulfato de zinco, $150 \mathrm{~g}$ de sulfato de manganês e $50 \mathrm{~g}$ de ácido bórico em 100 litros de água, 2 vezes ao ano na quantidade de 3 litros por planta. As folhas foram coletadas 45 dias após a última aplicação do segundo ano de experimento. Os resultados indicaram um aumento dos teores foliares de boro, manganês e zinco, comparado com a testemunha $\left(\mathrm{Zn}=15\right.$ para $43, \mathrm{Mn}=26$ para 53 e $\mathrm{B}=39$ para $\left.56 \mathrm{mg} \mathrm{kg}^{-1}\right)$, mas com relação à produção e peso médio de frutos não houveram aumentos.

Segundo Osaki (1991) aplica-se aos pomares de citros zinco uma única vez, na concentração de $0,35 \%$ de sulfato de zinco. Isto é suficiente para evitar carência por três anos. 
Cabrita (1993) afirma que o tratamento via foliar com sais demonstrou ser a melhor forma de aumentar os teores de $\mathrm{Zn}$ e $\mathrm{Mn}$, mantendo os niveis desses elementos numa faixa considerada de adequada a alta.

Machado (1991) estudou a aplicação de zinco via foliar em citros variedade Pera enxertada sobre limoeiro cravo. A concentração de $0,5 \%$ de sulfato de zinco foi suficiente para elevar os teores foliares deste nutrientes a níveis considerados adequados. A aplicação via solo não foi eficiente. Observou ainda que, a acidez dos frutos foi maior nos tratamentos onde houve aplicação foliar, e o peso de bagaço e a porcentagem de suco foram menores quanto maior a dose de zinco, aplicados no solo. As demais características estudadas (sólidos solúveis, diâmetro de frutos e produção de frutos) não foram afetados pelos tratamentos

Razeto et al. (1988) aplicaram sulfato de zinco, sulfato de manganês, tanto isolados, como combinados e na presença ou ausência de uréia, por dois anos, fazendo duas aplicações por ano. O experimento foi conduzido em pomar com sintomas de deficiência de zinco e manganês. Verificaram que houve um aumento nos teores de manganês e zinco nas folhas que receberam sulfato de zinco e manganês, mas a produção e diâmetro de frutos não apresentaram diferenças estatisticamente significativas em relação ao tratamento testemunha. Para o a segundo ano, houve efeito dos tratamentos tanto para os teores foliares dos micronutrientes, como para produção e diâmetro dos frutos. Embora há de se ressaltar que o trabalho não apresenta os dados de produção e sim um índice que estima a produção, e os autores não esclarecem como tal índice foi calculado. 


\subsection{Adubação Foliar com Manganês}

A ocorrência de deficiência de manganês em citros é comum. $O$ sintoma característico è o amarelecimento entre as nervuras das folhas, porem mais pálida e menos acentuada que as deficiência de zinco. Este sintoma é mais comum em solos alcalinos ou que receberam calagem excessiva, condições que diminuem a disponibilidade deste micronutriente. A maneira utilizada mais comum para corrigir a deficiência de manganês é a pulverização foliar com sulfato de manganês comercial (Camargo \& Silva, 1975).

Parker \& Southwick (1941) descreveram esta deficiência na Califórnia e em 1949 ela já era conhecida em todas as áreas de citros do mundo.

De acordo com Camp et al. (1941) os sintomas de deficiência de manganês manifestam-se nas folhas jovens e caracterizam-se pelo desenvolvimento de uma coloração verde mais clara entre as nervuras. As folhas jovens não possuem o brilho normal e quando entram em senescência tornam-se foscas e caem prematuramente. $\mathrm{O}$ aparecimento de manchas pardas distribuidas sobre as folhas e de pontuações mais claras nas áreas internervais já cloróticas, tem sido atribuido à deficiência de manganês.

Labanauskas et al. (1969) fazem referências às plantas indicadoras de deficiência de manganês e cita como plantas sensiveis, macieira, cerejeiras, citros, aveia, framboesa e a beterraba.

O controle da deficiência de manganês em pomares citricolas do Estado de São Paulo requer um programa adequado de adubação preventiva com manganês, para se evitar problemas de deficiência.

Instituto Interamericano de La Potassa (1958), diz que aplicações no solo de 30 a $50 \mathrm{~kg} \mathrm{ha}^{-1}$ de sulfato de manganês faz parte da 
adubação normal dos pomares da Flórida. Em solos muito calcários recomendamse adicionar de 1 a $5 \mathrm{Kg}$ de sulfato de manganês em 100 litros de água, neutralizados por 100 a $250 \mathrm{~g}$ de cal e aplicando-se a calda sobre as folhas.

Reitz (1958) recomenda para correção de deficiência de manganês a aplicação de sais de micronutrientes no solo quando este é ácido. E em solos alcalinos recomenda-se usar aplicações foliares.

Salibe (1974) recomenda o uso de $500 \mathrm{~g}$ de sulfato de manganês adicionados a $250 \mathrm{~g}$ de cal hidratada em 100 litros de água, para corrigir a deficiência de manganês.

Ben David (1975) relata que a aplicação no solo de compostos de manganês não têm apresentado muito sucesso; os quelatos de manganês não têm sido extensivamente experimentados em citros e somente as aplicações foliares com sulfato de manganês têm sido usadas para corrigir os sintomas de deficiência.

Labanauskas et al. (1969) encontraram que as pulverizações com manganês em qualquer combinação com zinco e nitrogênio aumenta a concentração de manganês nas folhas novas da vegetação subsequente e reduz o teor de zinco, cobre e nitrogênio. Na correção da deficiência de manganês, a mistura com uréia foi mais eficiente do que a aplicação de manganês isoladamente. A interação manganês-uréia foi altamente sinergística, entretanto o manganês apresentou ação antagônica sobre o nitrogênio, zinco e cobre, quando na mistura contém zinco e uréia.

Razeto \& Salas (1986), listaram a interação de magnésio, manganês e zinco aplicados via foliar através de diferentes fontes, em laranja Valência no Chile. Para o manganês, a correção do sintoma visual ocorreu mais rapidamente quando o manganês foi aplicado junto com outros elementos na 
solução, do que com o manganês aplicado sozinho. Tanto sulfato de manganês como quelato (Mn-EDTA) tiveram os mesmos resultados. A concentração de manganês nas folhas foi alto também para as folhas que surgiram após a pulverização na mesma estação de crescimento, mas foi menor para as brotações da estação seguinte.

Hilgeman \& Sharples (1968) estudaram o efeito da adubação foliar com manganês em pomeleiros no Arizona durante 11 anos. Nos dois primeiros anos foi usado quelado de $\mathrm{Mn}$ e nos seguintes o sulfato de manganês. Os autores notaram que os sintomas de deficiência variaram de intensidade de ano para ano e que nos anos de deficiência mais aguda as plantas tratadas diferiram das testemunhas. Entretanto, não houve diferença significativa em relação acidez total e sólidos solúveis do suco dos frutos.

\subsection{Adubação Foliar com Boro}

O boro é essencial para o desenvolvimento das plantes e na ausência dele, elas apresentam vários sintomas de deficiência. Mas, segundo vários autores, as funções deste micronutriente nas plantas não estão bem elucidadas.

Os sintomas gerais, mais comuns, da deficiência de boro são citados por Rodrigues (1974). As plantas têm desenvolvimento reduzido e às vezes secamento das extremidades. As folhas tornam-se menores, com ondulação do limbo, nervuras salientes e muitas vezes corticosas. Há grande queda de frutos e os que permanecem nas plantas têm tamanho reduzido, apresentando-se deformados e até com alguma goma externa quando a falta deste nutriente é aguda. Dentro dos frutos, no albedo e no centro, podem aparecer manchas de 
goma escuras, as sementes são em geral pequenas, escuras, mal formadas e envoltas em goma e a porcentagem de suco é reduzido.

As principais causas que provocam deficiência de boro estão em função da falta do elemento no solo, solubilização do boro em solos ácidos, imobilização do boro em solos alcalinos, solos ricos em matéria orgânica e pobres em material coloidal (Rivero ${ }^{1}$ citado por Dechen \& Neves, 1988).

No controle da deficiência de boro, tem-se que tomar muito cuidado com a dose a ser aplicada para não se ter problemas de toxidez. Rodrigues (1974) observou que sendo muito pequena a faixa de segurança entre a deficiência e o excesso de boro, as pulverizações de correção da deficiência não devem ultrapassar a proporção de 100g de bórax comercial para 100 litros de água.

Vitti (1992) cita que as principais funções do boro nas plantas de citros estão relacionadas com o tamanho e a qualidade dos frutos, porque o boro está ligado ao funcionamento e formação da parede celular, divisão celular, germinação do grão-de-pólem, crescimento do tubo polínico e formação de carboidratos.

Instituto Interamericano de La Potassa (1958) cita que a recomendação para o controle da deficiência de boro na Flórida é de 5 a $15 \mathrm{~kg}$ ha $a^{-1}$ por ano para a aplicação no solo ou pulverização das plantas com ácido bórico ou bórax, em soluções de $100 \mathrm{~g}$ em 100 litros de água.

Geus (1973) indica o uso de bórax tanto como adubo de solo, como na forma de adubação foliar na concentração de $1 \%$. Na Flórida as aplicações no solo são de cerca de 10 a $15 \mathrm{~kg} \mathrm{ha}^{-1}$ em solos arenosos e leves e de 50 a $60 \mathrm{~kg}$ ha ${ }^{-1}$ em solos adubados e argilosos. Na África do Sul, Barnard et al. (1973), testaram o uso de boro via foliar e via solo em laranjeira Washington Navel e

${ }^{1}$ RIVERO, J.M. del. Los estados de carência en los agrios. 2 ed. Madrid, ed. 1968. 510p. 
obtiveram maiores teores de boro nas folhas, quando a adubação foi feita via solo com bórax. Entretanto a aplicação foliar de bórax elevou o conteúdo total de ácido e reduziu os valores da relação açúcar/acidez do suco, retardando a maturação de grapefruit, segundo Deszyck \& Sites (1954).

Segundo Ducatti (1991), a aplicação de boro via solo com FTE 248, na dose de $80 \mathrm{~g}$ planta $^{-1}$ elevou o teor foliar deste micronutriente a níveis considerados adequados para a cultura, mas a sua aplicação via foliar não foi eficiente, pois os teores de boro nas folhas permaneceram inalterados.

Segundo o Grupo Paulista de Recomendação e Calagem para Citros (1994); em pomares deficientes em boro (abaixo de $0,2 \mathrm{mg} \mathrm{dm}^{-3}$ ), é recomendável a aplicação desse nutriente. Em pomares em formação, aplicar $0,75 \mathrm{~kg} \mathrm{ha}^{-1}$ de boro e, em produção, $1,5 \mathrm{~kg} \mathrm{ha}^{-1}$ de boro.

Com relação ao nivel crítico de boro, Trani (1983) cita o valor de 50ppm em folhas de brotação primaveril com cerca de 6 meses de idade, de ramos frutíferos ou não.

\subsection{Adubação Foliar com Produtos Biológicos}

Além da indicação de adubos minerais para a aplicação via foliar também têm sido indicado por fabricantes produtos para a adubação foliar que tem na sua composição aminoácidos, vitaminas e outros compostos, como por exemplo hormônios. Mesmo não tendo resultados de pesquisas sobre a eficiência e viabilidade econômica destes produtos, já existem vários destes disponiveis no mercado e que estão sendo utilizado pelos agricultores.

A origem do uso destes produtos está associado a trabalhos que mostraram que os seedlings e as raízes são capazes de absorver compostos 
orgânicos juntamente com os nutrientes. Por exemplo, Mori \& Nishizama (1979), constataram que as plantas de cevada, sob condições de altas temperaturas, absorvem compostos nitrogenados pelas raizes na seguinte ordem: $\mathrm{N}$-glutamina ou histidina $>$ nitrato/arginina $>$ nitrato/arginina $(1 / 1)>$ nitrato/arginina $(2)$.

Devido aos resultados dos trabalhos mencionados sobre a absorção de aminoácidos pelas raízes, alguns pesquisadores se interessaram em estudar o efeito da aplicação via foliar de aminoácidos sobre a produção de algumas culturas.

Acredita-se que o uso de aminoácidos pode ajudar a planta num determinado estágio de seu desenvolvimento. Castro (1991) comenta que, sobre condições de crescimento desfavoráveis, tais como baixas temperaturas, escassez de água e nutrientes, ocorre uma diminuição da síntese de vitaminas e que a aplicação de aminoácidos, pode ajudar a planta sob estas condições adversas.

Além desses efeitos, também foram feitas algumas pesquisas com a utilização de aminoácidos no controle de doenças de plantas. $\mathrm{Homa}^{2}$ et al. (1973), citados por Castro (1991), obtiveram resultados positivos no controle de brusone do arroz, com a utilização de valina e ácido láurico.

Em relação à nutrição de plantas existem muito poucos trabalhos onde houve a utilização de aminoácidos. Isto por que os nutrientes minerais são mais baratos que estes compostos orgânicos (aminoácidos), ou devido aos compostos orgânicos não serem superiores aos efeitos dos adubos normalmente utilizados.

Haque et al. (1971) verificaram que, no estado de "seedling", as plantas de arroz responderam a aplicação de ácidos aspártico e glutâmico, e no

\footnotetext{
${ }^{2}$ HOMMA, J.; SHIDA, T.; MISATO, T. Studies on the control of plant diseases by amino acid. Derivatives "Effect of $N$. laurayl
} 
estado reprodutivo, à aplicação de prolina. Concluíram que os aminoácidos podem ser aplicados em vários estágios de desenvolvimento da planta.

Melo et al. (1983) não verificaram efeitos significativos na produção e nos teores de N,P e $S$ no milho, quando aplicaram, por via foliar solução contendo cisteina.

A aplicação foliar de metionina na cultura de soja, segundo vários pesquisadores, não apresentou aumento na composição protéica dos grãos, entretanto outros autores constataram aumento nos teores de metionina e cisteína, tanto em condições de casa de vegetação quanto no campo (Castro, 1991).

Castro (1991) concluiu que para cultura do feijoeiro, tanto em aplicação nas sementes quanto na aplicação foliar, não deve ser recomendada a aplicação de metionina ou vitamina $B_{12}$, pois a aplicação destes produtos não aumentou nem a produtividade da cultura nem a qualidade das sementes.

Boaretto et al. (1990) aplicaram via foliar os aminoácidos: leucina, valina, prolina, triptofano, fenilalanina, tirocina, isoleucina e os produtos comerciais aminofértil e fertamin na cultura do feijão e não constataram efeito estatisticamente significativo dos tratamentos nas produções obtidas.

Recentemente têm sido empregado aminoácidos como agentes quelantes de micronutrientes na preparação de produtos para a adubação foliar. Está idéia tem sido explorada por firmas comerciais nos Estados Unidos da América, que apresentam produtos contendo aminoácidos e micronutrientes.

Os quelados de aminoácidos e micronutrientes são constituídos por ligação covalente com cátions divalentes, formando uma estrutura de anel heterocíclico, que facilita a passagem pela cutícula ( Ashmead, 1986). 
Foi demonstrado que 0 aminoácido sintético, denominado comercialmente de metalosate, penetra na folha a uma velocidade maior que por uma simples difusão. O metalosate (que contém ferro, zinco, manganês e cobre) tem a mesma velocidade de absorção que o Fe-EDTA (Hsu, 1986b).

Graff $^{3}$ citado por Hsu (1986b) constatou, em diferentes partes das plantas de tomate, que o quelado aminoácido-ferro foi absorvido e translocado com uma eficiência de $64 \%$ a mais que o Fe-EDTA e $56 \%$ a mais que sulfato ferroso. Também foi observado que os quelados aminoácidos-ferro e manganês foram melhor absorvidos que o ferro e manganês quelatizado com EDTA (Hsu, 1986b).

Hsu (1986b) constatou a eficiência do produto comercial metalosate nos rendimentos de arroz, feijão, tomate e algodão nos Estados Unidos da América e América Central. Os autores comentam que houveram incrementos na produção destas culturas de 6 a $30 \%$, mesmo nas plantas que não apresentavam sintomas de deficiência. Estes aumentos foram devidos a correção das deficiências, mas também ao resultado favorável de um balanço de micronutrientes.

Hsu (1986b) estudou o efeito do nitrogênio na absorção de ferro. Usaram três fontes de ferro quelatizado com aminoácidos, EDTA e sulfato e três niveis de nitrogênio $(100 ; 500 ; 1000 p p m)$. O ferro quelatizado foi absorvido em maior quantidade nos três níveis de nitrogênio.

No Egito, El-Fouly et al. (1988) constataram, que o uso na adubação foliar com quelados (os aminoácidos como agente quelante) contendo cálcio, magnésio, ferro, manganês, zinco e cobre, provocaram aumento na

\footnotetext{
${ }^{3}$ GRAFF, D. "Radioactive isotope studies in plants". In: ASHMEAD, D. (Ed.). Chelated Mineral Nutrition in Plants, Animals and Man. (Springfield: Charles, C. Thomas), 70, valine on rice blast ". Amm. Phytopathol. Soc. Japan, Toquio,n.39, p. $90-98,1973$
} 
produção das seguintes culturas; trigo $37 \%$, feijão $42,5 \%$, milho $19,3 \%$, arroz $25 \%$ e algodão $34 \%$.

Em frutiferas, Shazly (1986), também verificou aumento na produção, quando usou aminoácido como agente quelante, sendo o produto comercial denominado metalosate. Em laranjeira, o aumento na produção foi de $39,6 \%$ a $54,5 \%$, e na videira de 17,9 a $53,6 \%$, em figueira foi de 25,7 a $108 \%$ e na pereira o incremento ficou entre 18,74 a $79,36 \%$.

Miller \& Warnick ( 1986) estudaram a absorção de ferro por duas variedades de aveia. Constataram que a variedade não eficiente na absorção de ferro, apresentou teor de ferro em sua matéria seca comparável à de outra variedade eficiente na absorção de ferro, devido à aplicação de ferro quelatizado com aminoácidos.

\subsection{Adubação Foliar e sua Influência no Solo}

Em relação a este item, não há relatos na literatura de trabalhos científicos que tratem especificamente da adubação foliar e sua influência sobre teores dos nutrientes no solo. Alguns autores citam que na adubação foliar há um grande escorrimento da solução aplicada nas folhas para o solo. Stoler (1989), comenta em seu trabalho, que geralmente $50 \%$ da quantidade da solução empregada cai no solo. Havendo portanto uma absorção dos nutrientes tanto via foliar como via radicular. 


\section{MATERIAL E MÉTODOS}

\subsection{Experimento 1}

\subsubsection{Local}

O experimento foi conduzido em área particular, situada no município de Mogi Mirim, Estado de São Paulo, cujas coordenadas geográficas médias são: $22^{\circ} 42^{\prime}$ de latitude sul; $42^{\circ} 25^{\prime}$, de longitude oeste e $680 \mathrm{~m}$ de altitude.

\subsubsection{Clima}

A região de Mogi Mirim-SP apresenta clima característico do tipo Cwa (segundo classificação de Koeppen) tropical úmido, com inverno seco (junhojulho-agosto) e verão chuvoso (dezembro, janeiro e fevereiro). A umidade relativa do ar apresenta média anual de $74 \%$, tendo insolação real e potencial médias mensais de 201,9 e 365,1 horas, respectivamente. A temperatura média do ar durante o verão é de $24,0^{\circ} \mathrm{C}$ e no inverno é de $17,2^{\circ} \mathrm{C}$, apresentando uma média anual de $21,1^{\circ} \mathrm{C}$. 


\subsubsection{Solo}

O solo foi classificado como Podzólico Vermelho-escuro, textura argilosa. A Tabela 1 apresentam os resultados da análise química de terra, da área do experimento, feita antes de iniciar o experimento.

\subsubsection{Tratos culturais}

Foram utilizados os mesmos tratos culturais que eram normalmente utilizados na propriedade. Controlou-se apenas a parte de aplicação de micronuturientes via foliar. As laranjeiras, que tinham 5 anos de idade no início do experimento, foram plantadas num espaçamento de 8 metros entre linhas. $\mathrm{Na}$ linha as plantas estavam espaçadas alternadamente de 5 e 1,8 metros. Todos os tratamentos receberam os mesmos tratos fitossanitários e a mesma calagem e adubação de solo.

\subsubsection{Tratamentos}

Os tratamentos foram dispostos em blocos ao acaso com 4 repetições. As parcelas continham 20 plantas, sendo 12 plantas úteis e 8 plantas consideradas bordaduras. Os tratamentos estão apresentados na Tabela 2 . 
Tabela 2. Tratamentos utilizados no experimento $1 \mathrm{e}$ as quantidades aplicadas dos micronutrientes, considerando-se a aplicação de $2000 \mathrm{~L} \mathrm{ha}^{-1}$ de solução por vez.

\begin{tabular}{|c|c|c|c|}
\hline & B & $\mathrm{Mn}$ & $\mathrm{Zn}$ \\
\hline & \multicolumn{3}{|c|}{ Quantidades $\left(\mathrm{g} \mathrm{ha}^{-1}\right)$} \\
\hline \multicolumn{4}{|l|}{ 1. Testemunha ${ }^{1}$} \\
\hline 2. Produto comercial ${ }^{4}\left(4 \mathrm{~L} \mathrm{ha}^{-1}\right)$ & 40 & 80 & 200 \\
\hline 3. Produto comercial ${ }^{4}\left(8 \mathrm{~L} \mathrm{ha}^{-1}\right)$ & 80 & 160 & 400 \\
\hline 4. Produto comercial ${ }^{4}\left(12\right.$ L ha $\left.^{-1}\right)$ & 120 & 240 & 600 \\
\hline 5. Produto comercial ${ }^{4}\left(16 \mathrm{~L} \mathrm{ha}^{-1}\right)$ & 160 & 320 & 800 \\
\hline 6. Produto comercial ${ }^{4}\left(20 \mathrm{~L} \mathrm{ha}^{-1}\right)$ & 200 & 400 & 1000 \\
\hline 7. Produto comercial ${ }^{4}\left(24 \mathrm{~L} \mathrm{ha}^{-1}\right)$ & 240 & 480 & 1200 \\
\hline 8. Recomendação Técnica ${ }^{(2)}$ & 340 & 1040 & 1200 \\
\hline 9. Análise foliar ${ }^{(3)}$ & & & \\
\hline
\end{tabular}

\section{OBS:}

1- A testemunha não recebeu adubação foliar

2. O tratamento convencional é a aplicação da recomendação contida na Tabela 4

3- No tratamento análise foliar, a recomendação de nutrientes foi em função da diagnose foliar feita antes de iniciar o experimento.

4- $O$ produto comercial tem o nome de AJIFOL-L, e suas características estão contidas na Tabela 3. Trata-se de um fertilizante organo-mineral misto (registrado no MA sob o $n^{\circ}$ 14780.)

A Tabela 4 apresenta a recomendação de aplicação dos micronutrientes via foliar em citros para o Estado de São Paulo, (Grupo Paulista de Adubação e Calagem para Citros, 1994). 
Tabela 3. Composição do produto comercial

\begin{tabular}{lrll}
\hline Elemento ou substância & $\%$ & Aminoácidos e ácidos orgânicos \\
\cline { 1 - 2 } $\mathrm{N}$-total & 10 & Ácido glutâmico \\
$\mathrm{K} 2 \mathrm{O}$ & 2 & Ácido acético \\
$\mathrm{Zn}$ & 5 & L-asparagina \\
$\mathrm{Mn}$ & 2 & & L-alanina \\
$\mathrm{B}$ & 1 & L-valina \\
$\mathrm{Aminoácido} \mathrm{total}$ & 8 & L-leucina \\
$\mathrm{Matéria} \mathrm{orgânica} \mathrm{total}$ & 40 & L-isoleucina \\
$\mathrm{Na}$ & 2 & L-glicina \\
$\mathrm{S}$ & 13 & L-treonina \\
$\mathrm{Cl}$ & 2 & L-arginina \\
$\mathrm{Ca}$ & $630 \mathrm{ppm}$ & L-lisina \\
$\mathrm{Mg}$ & $600 \mathrm{ppm}$ & L-serina \\
$\mathrm{Fe}$ & $500 \mathrm{ppm}$ & L-fenilanina \\
$\mathrm{Cu}$ & $2 \mathrm{ppm}$ & L-prolina \\
$\mathrm{Ni}$ & $2 \mathrm{ppm}$ & L-histidina \\
& & L-metionina \\
\hline
\end{tabular}


Tabela 4. Composição da solução de micronutrientes para a aplicação via foliar.

\begin{tabular}{lcc}
\hline Fontes & $\begin{array}{c}\text { Concentração } \\
(\%)\end{array}$ & $\begin{array}{c}\text { Quantidades por } 100 \text { litros de água } \\
(\mathrm{g})\end{array}$ \\
\hline Sulfato de zinco & 0,30 & 300 \\
$\begin{array}{l}\text { Sulfato de } \\
\text { manganês }\end{array}$ & 0,20 & 200 \\
Ácido bórico & 0,08 & 80 \\
Uréia & 0,50 & 500 \\
$\begin{array}{l}\text { Cloreto de } \\
\text { potássio }\end{array}$ & 0,25 & 250 \\
\hline
\end{tabular}

Fonte: Grupo Paulista de Adubação e Calagem para Citros, 1994.

Para tratamento 9 , fez-se previamente a diagnose foliar, afim de verificar os teores de micronutrientes nas plantas, cujos resultados estão contidos na Tabela 5, que permitiram determinar a recomendação de adubação foliar, (Grupo Paulista de Adubação e Calagem para Citros, 1994). Aplicou-se sulfato de zinco, ácido bórico e uréia, nas dosagens recomendadas pelo Grupo Paulista de Adubação e Calagem para Citros (1994) e acrescentou sulfato de magnésio na

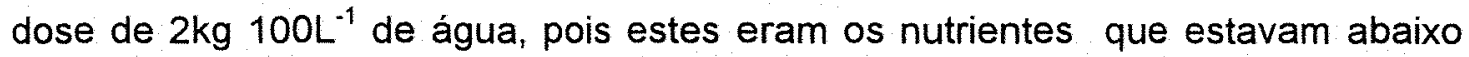
da faixa foliar ótima antes de iniciar o experimento (Tabela 6). 
Tabela 5. Resultado da Análise de folha do pomar, antes de iniciar o Experimento

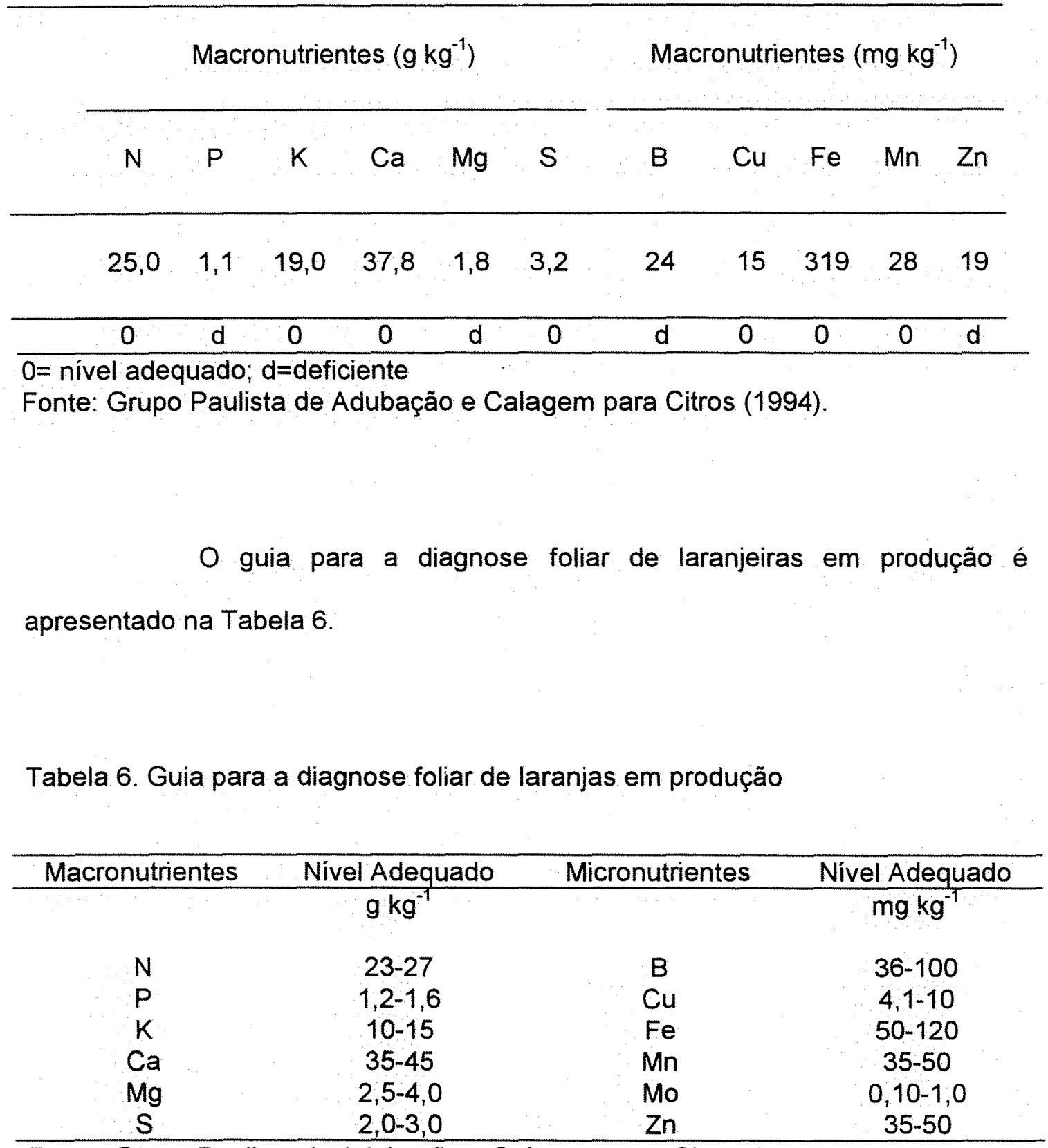

Fonte: Grupo Paulista de Adubação e Calagem para Citros (1994). 


\subsubsection{Aplicações}

Foi feita a pulverização das plantas, tomando-se o cuidado de atingir todas as suas partes, aplicando-se cada vez um total de 2000 litros ha ${ }^{-1}$, dando uma média de 8 litros planta ${ }^{-1}$ e 160 litros parcela ${ }^{-1}$. Foram feitas 4 aplicações foliares em todos os tratamentos nas seguintes datas: $30-10-1993$, 21-02-1994, 14-11-1994 e 28-02-1995.

\subsubsection{Avaliações}

\subsubsection{Amostragens de Folhas e Análise Foliar}

Foram realizadas amostragens foliares em $30 / 11 / 93$, um mês após a primeira aplicação, 16/04/94, dois meses após a segunda aplicação e a ultima em $28 / 03 / 95$, um mês após a quarta aplicação. A amostragem de folha foi feita da seguinte maneira: coletaram-se a terceira e quarta folha em ramos frutiferos, num total de 4 folhas por planta, sendo 1 em cada quadrante e na altura mediana da copa (Grupo Paulista de Adubação e Calagem para Citros, 1994).

Após a realização da amostragem as folhas foram lavadas com água e detergente neutro, sendo em seguida colocadas para secar em estufa com circulação forçada de ar a $70^{\circ} \mathrm{C}$. O material foi moído e após o processo de digestão nitroperclórica, foram determinados os macronutrientes $(\mathrm{P}, \mathrm{K}, \mathrm{Ca}, \mathrm{Mg}$ e S) e os micronutrientes ( $\mathrm{Mn}, \mathrm{Fe}, \mathrm{Zn}$ e $\mathrm{Cu}$ ). Para a determinação do nitrogênio foi feita a digestão sulfúrica e para a determinação do boro foi feita a digestão via seca (Malavolta e Vitti, 1989) 


\subsubsection{Colheita e Análise de Frutos}

A colheita e a pesagem dos frutos de cada parcela foi realizada em novembro de 1994 e em agosto de 1995.

Na semana anterior às colheitas foram realizadas amostragens de frutos para análises tecnológicas de rotina acidez, sólidos solúveis, ratio, porcentagem de suco, diâmetro dos frutos, peso dos frutos, peso do bagaço (Mendes 1936).

$\mathrm{Na}$ Tabela 7 são apresentados os parâmetros considerados ideais para a laranja Pera: produção média de frutos, peso médio dos frutos, quantidade de suco, brix, acidez, ratio, diâmetro de frutos (Figueiredo, 1991)

Tabela 7. Produção média de frutos e parâmetros tecnológicos, para laranja Pera.

\begin{tabular}{rrrrrr}
\hline Produção & $\begin{array}{c}\text { Peso médio } \\
\text { dos frutos }\end{array}$ & $\begin{array}{c}\text { Quantidade de } \\
\text { suco }\end{array}$ & Brix & Acidez & Ratio \\
$\mathrm{kg} \mathrm{planta}{ }^{-1}$ & $\mathrm{~g}$ & & $\%$ & & \\
\hline 250 & 145 & 52 & 11,8 & 0,95 & 12,50 \\
\hline
\end{tabular}

Fonte: Figueiredo (1991)

Foram colhidos 10 frutos de cada árvore. Determinaram-se:

a) peso médio dos frutos: Para a avaliação do peso dos frutos utilizou-se de uma balança, sendo o resultado expresso em gramas.

b) medidas de comprimento e diâmetro dos frutos: Foi utilizado um paquímetro, sendo os resultados expressos em $\mathrm{mm}$. 
c) Extração de suco: Extraiu-se o suco através de um espremedor elétrico, sendo o suco utilizado para análise de sólidos solúveis e acidez.

d) Peso do bagaço: Utilizou-se de uma balança, sendo o resultado expresso em gramas.

e) Sólidos solúveis ( Brix): Avaliou-se o teor de sólidos solúveis utilizando-se um refratômetro de laboratório.

f) Acidez: Foi empregado o método da titulação com $\mathrm{NaOH}$ a $0,1 \mathrm{~N}$ e fenolftaleina a $0,1 \%$, sendo o seu valor calculado mediante uso da fórmula: Acidez $=0,64 \times \mathrm{ml}$ soda $($ gasta $) / \mathrm{ml}$ suco $(20 \mathrm{ml})+1 / 10$ brix livre

f) Ratio: Para determinação do ratio empregou-se a seguinte relação:

$$
\text { Ratio= teor de sólidos solúveis/acidez corrigida }
$$

\subsubsection{Análise Estatística dos Resultados Obtidos}

Os dados obtidos no experimento 1 , foram analisados conforme 0 esquema estatístico de blocos ao acaso com 9 tratamentos e 6 repetiçóes. A análise estatística dos resultados foi efetuada de acordo com o apresentado na Tabela 8. 
Tabela 8. Modelo estatístico: causas da variação e graus de liberdade

\begin{tabular}{lc}
\hline $\begin{array}{l}\text { Causas da } \\
\text { variação }\end{array}$ & Graus de liberdade \\
\hline Tratamentos & 8 \\
Blocos & 5 \\
Resíduos & 40 \\
\hline Total & 53 \\
\hline
\end{tabular}

\subsection{Experimento 2}

\subsubsection{Local}

O experimento foi realizado em uma fazenda produtora de laranja no município de Araraquara, que tinha pomares de diversas idades.

\subsubsection{Idades dos Pomares}

As idades das laranjeiras dos pomares utilizados estão apresentados na Tabela 9. A área testemunha amostrada era em local bem próximo aos pomares de laranja, mas que nunca tinha sido utilizado como pomar 
anteriormente, sendo que na época da coleta das amostras a cultura presente era a Brachiaria decumbens.

Tabela 9. Idades dos pomares.

\begin{tabular}{cc} 
Variedade copa & Porta enxerto \\
\hline Área sem Citros & limoeiro cravo \\
Variedade Pera com três anos & limoeiro cravo \\
Variedade Pera com quatro anos & limoeiro cravo \\
Variedade Pera com seis anos & limoeiro cravo \\
Variedade Pera com sete anos & limoeiro cravo \\
Variedade Pera com oito anos & tangerina cleopatra \\
Variedade Natal com onze anos & tangerina cleopatra \\
Variedade Natal com doze anos & limoeiro cravo \\
Variedade Pera com catorze anos & limoeiro cravo \\
Variedade Pera com vinte anos &
\end{tabular}

\subsubsection{Avaliações}

\subsubsection{Diagnose Foliar}

Foi feita uma análise química das folhas de cada pomar, para verificar os teores dos micronutrientes e possivelmente auxiliar na interpretação dos resultados das análise de solo. A amostragem foi feita em abril de 1994 na mesma época da amostragem dos solos e da seguinte forma: coletaram-se a terceira ou quarta folha dos ramos que apresentava frutos, sendo uma folha em cada quadrante na posição mediana da planta (Grupo Paulista de Adubação e 
Calagem para Citros, 1994). Para cada repetição constou de 6 plantas, totalizando 24 folhas por repetição e 96 folhas por pomar. O procedimento de análise das folhas foi idêntico ao citado no item 3.1.7.1.

\subsubsection{Análise de Solo}

A amostragem na profundidade de $0-10 \mathrm{~cm}$ do solo foi feita com sonda, em cada pomar escolheram-se ao acaso 8 plantas, e em relação a cada planta as amostras foram colhidas em três posições diferentes: perto do colo (aproximadamente $5 \mathrm{~cm}$ ), no final da projeção da copa e na entrelinha. As amostras de solo retiradas em cada posição formavam a amostra composta. Foram feitas 4 repetições, sendo que este procedimento foi igual para cada pomar escolhido. Foi feita também uma amostragem de solo na profundidade de $0-10 \mathrm{~cm}$, em cada pomar, com o objetivo de se obter a caracterização química de cada pomar. Os resultados são apresentados na Tabela 10.

Nas amostras coletadas nas três posições em relação à planta determinaram-se: boro, manganês, zinco, ferro e cobre. $\bigcirc$ teor de boro no solo foi determinado no extrato obtido pela solução extratora de $\mathrm{CaCl}_{2} 2 \mathrm{H}_{2} \mathrm{O} \quad 0,1 \%$, em uma relação solução extratora/solo de $2 / 1(40 \mathrm{ml}$ de solução extratora/20ml de solo). Quantificou-se o teor de boro em espectrofotômetro com filtro de $420 \mathrm{~nm}$, (Cruz \& Ferreira, 1984). No caso do ferro, cobre, manganês e zinco foi feita através da extração com solução de DTPA-TEA, relação solução extratora/solo 2/1 ( $20 \mathrm{ml}$ de solução extratora/10ml de solo). A quantificação dos teores foi feita em espectrofotômetro de absorção atômica, com lâmpada específica para micronutriente (Lindsay \& Norwwell, 1978). 
Os resultados dos teores de micronutrientes foram analisados e comparados com a interpretação dos teores de micronutrientes no solo, apresentado na Tabela 11.

Tabela 10. Resultado da análise química do solo na profundidade de $0-10 \mathrm{~cm}$ utilizada no experimento

\begin{tabular}{|c|c|c|c|c|c|c|c|c|c|c|}
\hline \multirow[t]{2}{*}{ Idade } & $\mathrm{PH}$ & MO & $P$ & $\mathrm{~K}$ & $\mathrm{Ca}$ & $\mathrm{Mg}$ & $\mathrm{H}+\mathrm{Al}$ & $S B$ & $T$ & \multirow{2}{*}{$\begin{array}{l}\text { V } \\
\% \\
\end{array}$} \\
\hline & & $\mathrm{g} \mathrm{kg}^{-1}$ & $\mathrm{mg} \mathrm{dm}^{-3}$ & ב-ביב-ב & 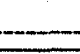 & $-\mathrm{mmo}$ & $\mathrm{dm}^{-3}-$ & & -..... & \\
\hline $0^{1}$ & 4,1 & 27 & 4 & 1,4 & 20 & 10 & 98 & 31 & 129 & 24 \\
\hline 3 & 5,6 & 22 & 65 & 2,5 & 45 & 15 & 28 & 63 & 91 & 69 \\
\hline 4 & 5,8 & 20 & 23 & 2,2 & 57 & 19 & 26 & 78 & 104 & 75 \\
\hline 6 & 5,9 & 21 & 39 & 2,5 & 53 & 17 & 26 & 73 & 99 & 74 \\
\hline 7 & 5,9 & 11. & 108 & 3,5 & 85 & 11 & 24 & 99 & 124 & 81 \\
\hline 8 & 6,0 & 16 & 14 & 4,1 & 38 & 16 & 25 & 58 & 83 & 70 \\
\hline 11 & 5,7 & 16 & 72 & 2,8 & 65 & 15 & 29 & 83 & 112 & 74 \\
\hline 13 & 6,1 & 22 & 44 & 3,3 & 58 & 20 & 25 & 81 & 106 & 76 \\
\hline 14 & 5,7 & 16 & 22 & 2,4 & 56 & 17 & 29 & 75 & 104 & 72 \\
\hline 20 & 6,0 & 22 & 28 & 2,3 & 42 & 18 & 24 & 62 & 86 & 72 \\
\hline
\end{tabular}

(1) Refere-se a área testemunha, ainda não cultivada com laranjeira

Tabela 11. Teores dos micronutrientes no solo.

\begin{tabular}{lccc}
\hline & Baixo & Médio & Alto \\
\hline & $<$ & $-\mathrm{mg} \mathrm{dm}^{-3}$ & \\
Boro & $<0,2$ & $0,2-0,6$ & $>0,6$ \\
Cobre & $<0,3$ & $0,3-1,0$ & $>1,0$ \\
Manganês & $<1,5$ & $1,5-5,0$ & $>5,0$ \\
Zinco & $<0,7$ & $0,7-1,5$ & $>1,5$ \\
& & & \\
\hline
\end{tabular}




\section{RESULTADOS E DISCUSSÃO}

\subsection{Experimento I}

\subsubsection{Análise Foliar}

Os resultados da análise foliar das amostras colhidas um mês após a primeira aplicação dos adubos foliares são apresentados na Tabela 12 .

Para as médias dos teores de macronutrientes de plantas $(N, P, K$, $\mathrm{Ca}, \mathrm{Mg}$ e S) não houveram diferenças estatisticamente significativas. Isto ocorreu porque as quantidades de macronutrientes aplicadas na cultura, tanto através do produto comercial como nos casos da recomendação técnica e do tratamento denominado de análise foliar (magnésio) são muito baixas, praticamente insignificantes diante dos conteúdos foliares dos macronutrientes dos citros. Podese constatar pelos resultados referentes aos macronutrientes na Tabela 12, que as plantas já se encontravam adequadamente nutridas quanto a $N, K, C a$ e , pois seus niveis estavam dentro da faixa considerada adequado. Para o $\mathrm{P}$ e $\mathrm{Mg}$ os teores estão bem próximos do nivel adequado, segundo os padrões do (Grupo Paulista de Adubação e Calagem para Citros, 1994).

No caso dos micronutrientes $\mathrm{Fe}$ e $\mathrm{Cu}$, verifica-se que não houveram diferenças estatisticamente significativas para os teores nas folhas, o que também era de se esperar, pois as formulações dos adubos foliares aplicadas não os contém. Para o B e o $\mathrm{Zn}$ houveram aumentos dos teores foliares devido à aplicação dos adubos foliares. Os teores destes micronutrientes estavam 


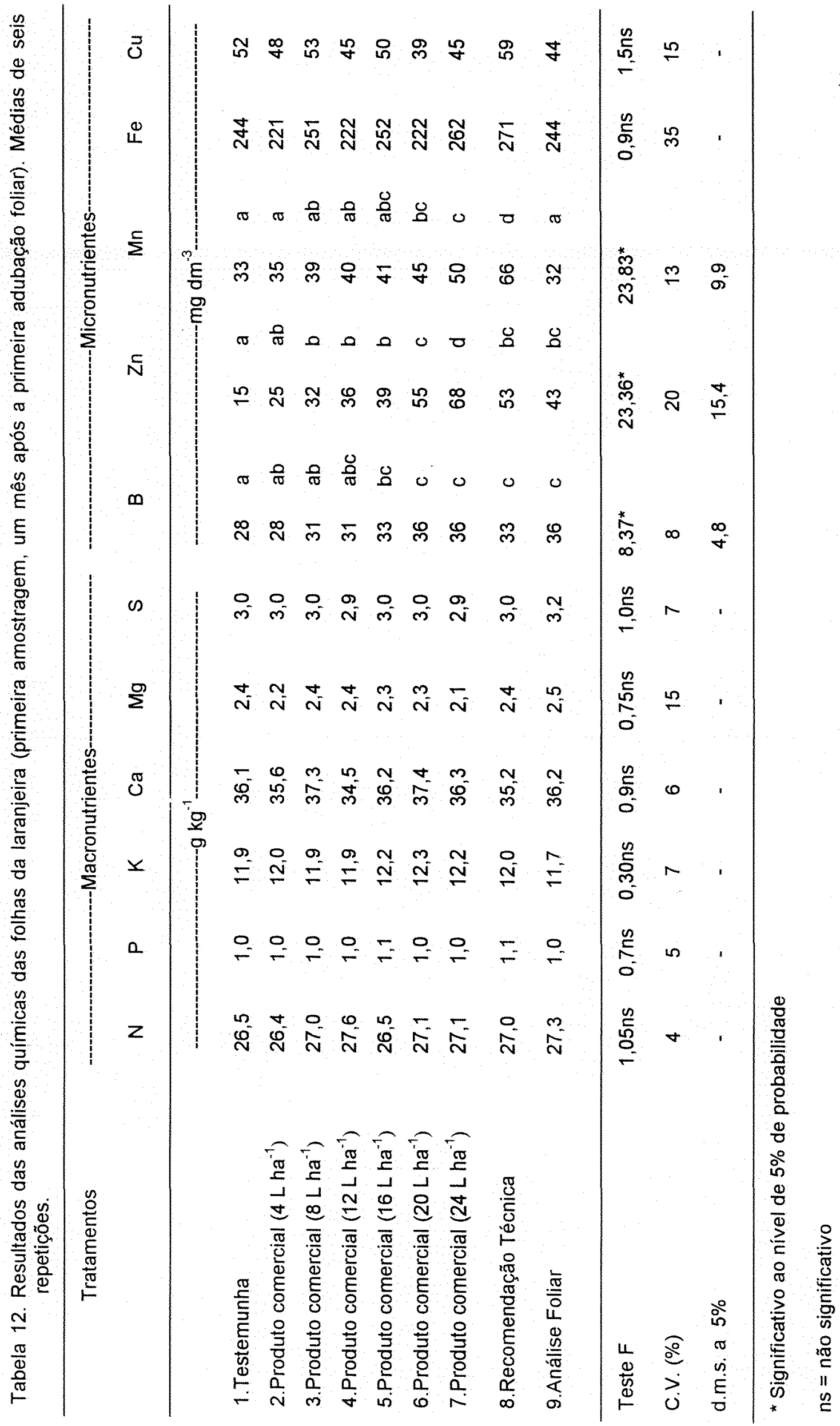


abaixo da faixa adequada (Grupo Paulista de Adubação e Calagem para Citros, 1994) e as aplicações dos produtos elevaram os seus teores a niveis considerados adequados. No caso do produto comercial foram necessários $4 \mathrm{~L} \mathrm{ha}^{-1}$ e $8 \mathrm{~L} \mathrm{ha}^{-1}$ para que os níveis atingissem a faixa adequada de zinco e boro, respectivamente. Observa-se diferença estatisticamente significativa entre os teores foliares médios dos tratamentos, sendo que os maiores teores de $\mathrm{B}$ e $\mathrm{Zn}$, foram obtidos naquele que recebeu a maior dose de produto comercial e nos tratamentos denominados de recomendação técnica e análise foliar. No caso do $\mathrm{Mn}$ também verifica-se diferença estatisticamente significativa entre as médias de teores foliares dos diferentes tratamentos. O tratamento que apresentou o maior teor de manganês foi o tratamento denominado recomendação técnica $\left(66 \mathrm{mg} \mathrm{dm}^{-3}\right)$.

$\mathrm{Na}$ Tabela 13 encontram-se os dados da análise de folhas referentes a segunda amostragem, feita 2 meses após a segunda adubação foliar. Observa-se que para os macronutrientes os dados são praticamente os mesmos da primeira amostragem, ou seja não houveram efeitos entre os tratamentos. Mesmo porque o tempo entre uma aplicação e a outra foi muito curto e, como dito anteriormente, o produto comercial apresenta pequenas quantidades de macronutrientes. A recomendação técnica, que apresenta uréia na formulação, a quantidade de nitrogênio aplicada foi pequena, sendo insuficiente para alterar os teores foliares. Até mesmo no caso do magnésio, que foi incluído no tratamento denominado de análise foliar, não apresentou diferença estatisticamente significativa entre os teores foliares.

Para os teores foliares de $\mathrm{Fe}$ e $\mathrm{Cu}$ verifica-se pelos resultados que não houveram diferenças estatisticamente significativas entre os tratamentos, concordando também com o dados da primeira amostragem. Houve uma variação 


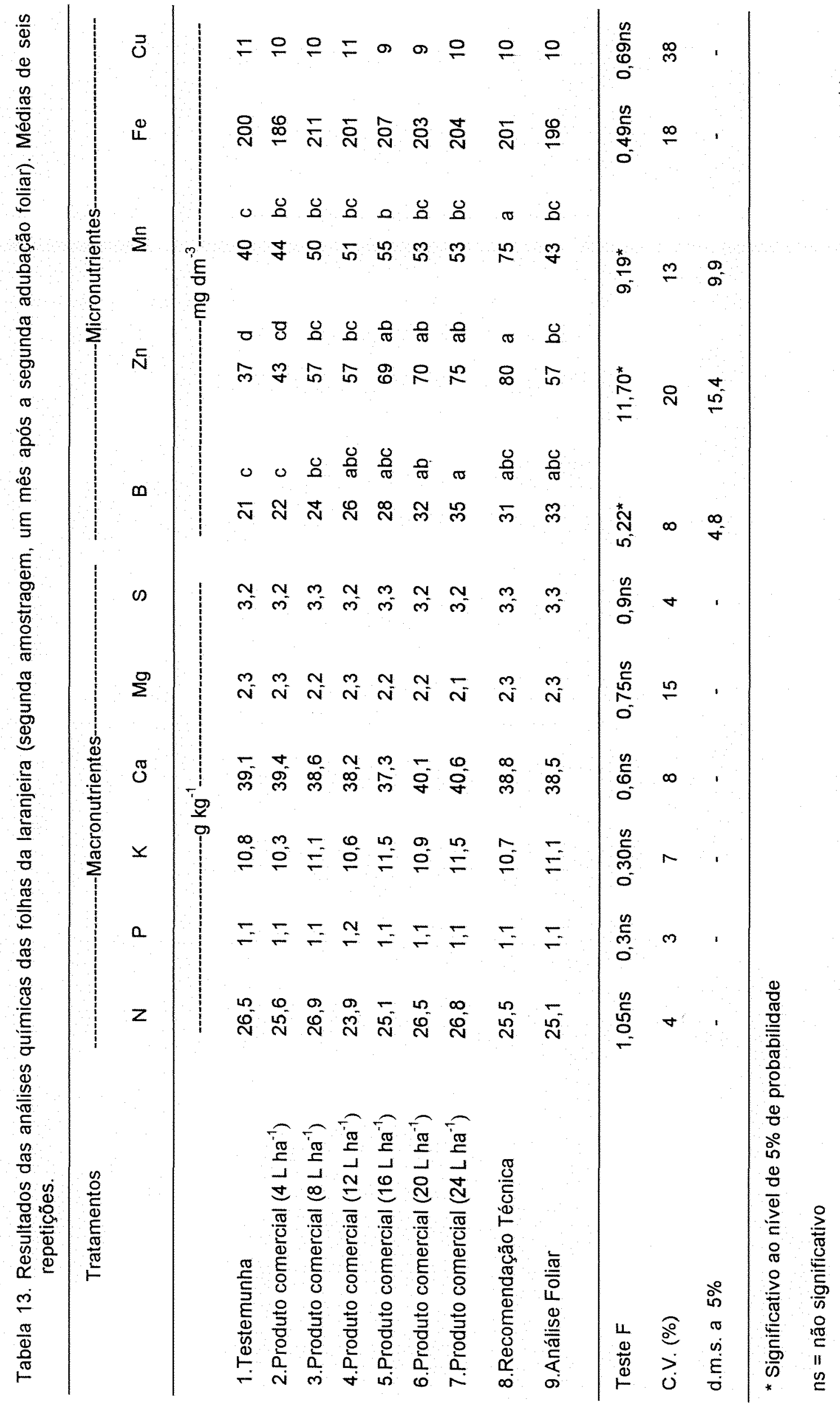


muito grande entre os teores de $\mathrm{Cu}$ da primeira para a segunda amostragem, devido uma aplicação de fungicida cúprico no pomar para controle da verrugose pouco antes da primeira amostragem.

Os teores de $\mathrm{B}, \mathrm{Zn}$ e $\mathrm{Mn}$ apresentaram diferenças estatisticamente significativas entre os tratamentos, ocorrendo um aumento dos teores foliares de acordo com a dose do produto comercial, com aumento de 14,38 e $13 \mathrm{mg} \mathrm{dm}$ respectivamente para $B, Z n$ e $M n$, entre a testemunha e a maior dose do adubo foliar. Estes dados indicam que há respectivamente aumentos de 0,6-1,6 e 0,5 mg $\mathrm{dm}^{-3}$ no teor foliar de $\mathrm{B}, \mathrm{Zn}$ e $\mathrm{Mn}$, para cada litro do produto aplicado por hectare. Comparando-se as médias dos teores foliares do tratamento que recebeu a maior dose do produto comercial $\left(24 \mathrm{~L} \mathrm{ha}^{-1}\right)$ e do tratamento denominado recomendação técnica verifica-se que, não houve diferença estatisticamente significativa. Apenas no caso do $B$, na primeira amostragem, verifica-se superioridade do produto comercial $\left(24 \mathrm{~L} \mathrm{ha}^{-1}\right)$, sobre a recomendação técnica, nos demais casos há inclusive uma tendência de superioridade da recomendação técnica sobre a dose maior do produto comercial ( $24 \mathrm{~L} \mathrm{ha}^{-1}$ ).

Comparando-se a primeira com a segunda amostragem verifica-se que os teores da segunda amostragem foram superiores para $\mathrm{Zn}$ e $\mathrm{Mn}$, e para o B ocorreu o inverso, pois os teores da segunda amostragem são inferiores aos da primeira. Mas deve-se ressaltar que as diferenças entre os teores da primeira e segunda amostragem são muito pequenas, para os 3 micronutrientes.

Os resultados da Tabela 14 , refere-se a terceira amostragem de folhas, ou a primeira na safra 94/95. Verifica-se novamente que para os macronutrientes não houveram diferenças estatisticamente significativas entre teores destes obtidos nos tratamentos utilizados. Os teores continuam dentro do 
limite considerado adequado. Apenas o teor de Mg está um pouco abaixo do nível adequado, inclusive para o tratamento denominado de análise foliar que recebeu Mg nas aplicações foliares. Portanto a aplicação foliar de $\mathrm{Mg}$ não foi suficiente para elevar os teores de $\mathrm{Mg}$ nas folhas a niveis adequado.

Os micronutrientes $\mathrm{Cu}$ e $\mathrm{Fe}$ continuaram apresentando niveis adequados, concordando com o dados da primeira e segunda amostragens. Os teores foliares de $\mathrm{B}, \mathrm{Zn}$ e $\mathrm{Mn}$ apresentaram diferenças estatisticamente significativas entre os tratamentos, concordando também com os resultados do primeiro ano. Os dados mostraram que houve um efeito da adubação foliar, apresentando diferenças estatisticamente significativa entre a testemunha e o tratamento 7 (24 $\mathrm{L} \mathrm{ha}^{-1}$ do produto comercial), mas que não há diferença estatisticamente significativa entre 0 tratamento 7 e 0 tratamento 9 (recomendação técnica). É importante ressaltar que nas 3 amostragens 0 B da testemunha apresentou teores abaixo do nivel considerado adequado. $O$ zinco encontrava-se abaixo da faixa adequada somente na primeira amostragem e o manganês sempre esteve dentro da faixa considerado adequada, de acordo com os índices do Grupo Paulista de Adubação e Calagem para Citros (1988). Na literatura há inúmeros trabalhos que demonstram a eficácia da adubação foliar com micronutrientes em elevar os teores foliares (Labanauskas \& Puffer, 1964; Labanauskas et al., 1969; Kotur, 1984; Razeto \& Salas., 1986; Razeto et al., 1988; Machado, 1993). 


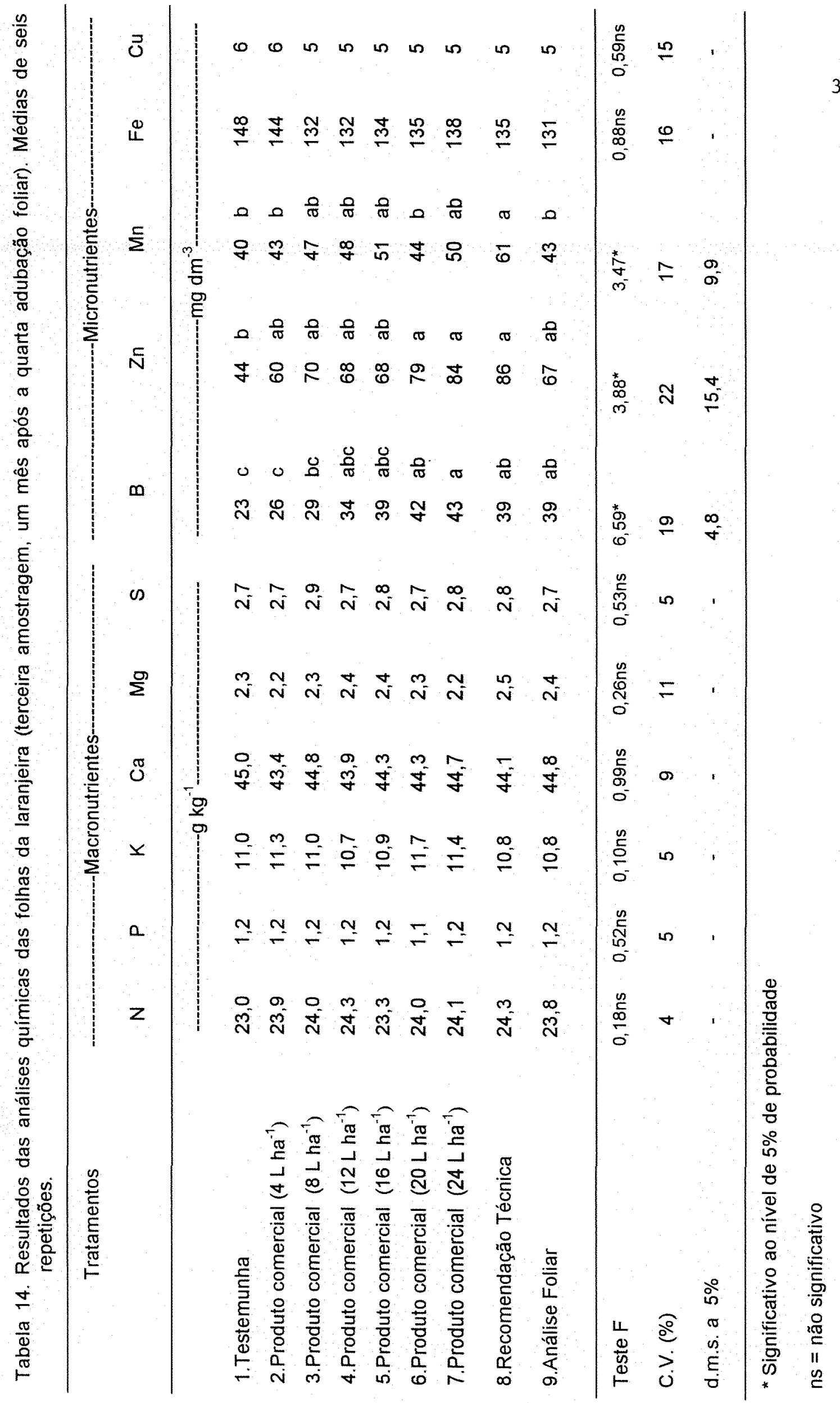




\subsection{Produção e Análises Tecnológicas dos Frutos}

$\mathrm{Na}$ Tabela 15 são apresentados os dados referentes a produtividade de frutos e parâmetros tecnológicos avaliados para frutos de laranja. Em nenhum dos parâmetros avaliados houveram diferenças estatisticamente significativas, concordando com Razeto et al. (1988). A ausência de resposta pode ser explicada por tratar-se de uma cultura perene que apresentava desde o início do experimento teores de nutrientes nas folhas considerados adequados para macro e micronutrientes, exceto para para boro e zinco. Os resultados indicam portanto, que o pomar vinha sendo bem conduzido, quanto a adubação. Os parâmetros tecnológicos obtidos estão de acordo com os parâmetros considerado normais (Figueiredo, 1991). Apenas a produtividade não foi boa, ficando abaixo da produtividade considerada adequado (Figueiredo, 1991). Embora deve-se considerar a idade das plantas, pois estas ainda encontram-se em início de produção, plantas de 5 anos, que ainda não haviam atingido a capacidade máxima de produção.

A Tabela 16 apresenta os dados referentes a produção e aos parâmetros tecnológicos de frutos de laranja da colheita do segundo ano de experimentação. Observa-se novamente que os tratamentos não apresentaram diferenças estatisticamente significativas em todos os parâmetros avaliados.

Comparando-se os resultados da primeira e segunda colheita, verifica-se um decréscimo de produção na segunda colheita, pois na segunda colheita foi colhido apenas $70 \%$ dos frutos aproximadamente, porque os $30 \%$ restantes ainda não estavam no ponto de colheita. Dentre os parâmetros avaliados, apenas o diâmetro dos frutos praticamente não variou entre a primeira 
consequentemente a acidez foi maior e o ratio menor. A porcentagem de suco também apresentou menores valores na segunda colheita. Para peso médio de frutos os teores foram maiores na segunda safra. As diferenças entre os parâmetros tecnológicos avaliados na segunda safra, comparado com os parâmetros tecnológicos da primeira safra, foram relativamente pequenas. Explica-se as diferenças nos valores de brix e acidez entre a primeira e a segunda colheita pela época de colheita, uma em novembro e a outra em agosto. $\mathrm{Na}$ colheita feita em novembro os frutos estavam bem mais maduros do que na colheita feita em agosto. Os parâmetros tecnológicos da primeira e segunda colheitas são considerados normais (Figueiredo, 1991). Para produção dos frutos, diâmetro de frutos e parâmetros tecnológicos não houveram diferenças estatisticamente significativas entre os tratamentos, concordando com os dados do primeiro ano, mas discordando com os dados de Razeto et al. (1988), que observaram diferenças estatisticamente significativas para produção de frutos e diâmetro de fruto no segundo ano de estudo. 


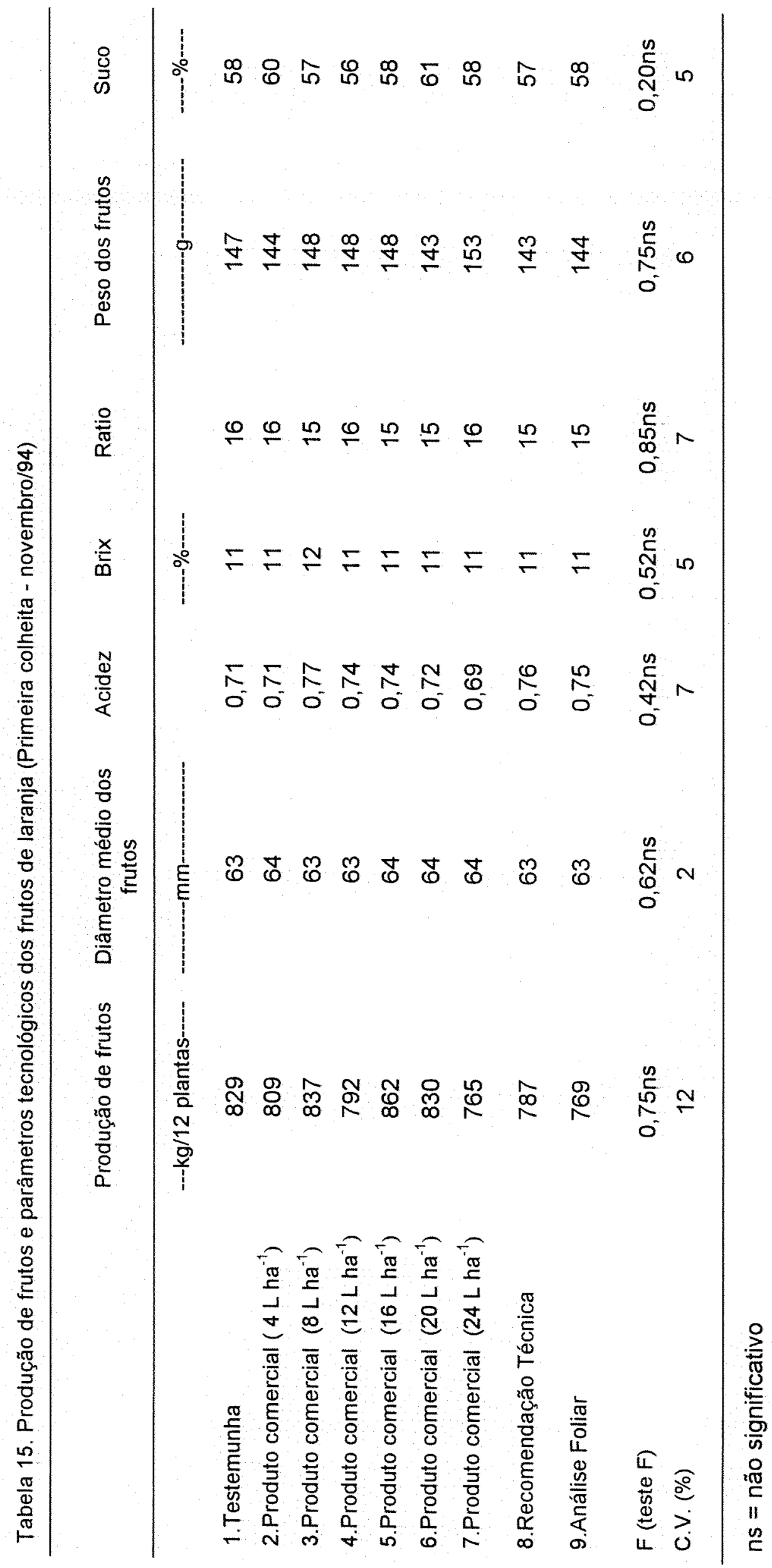




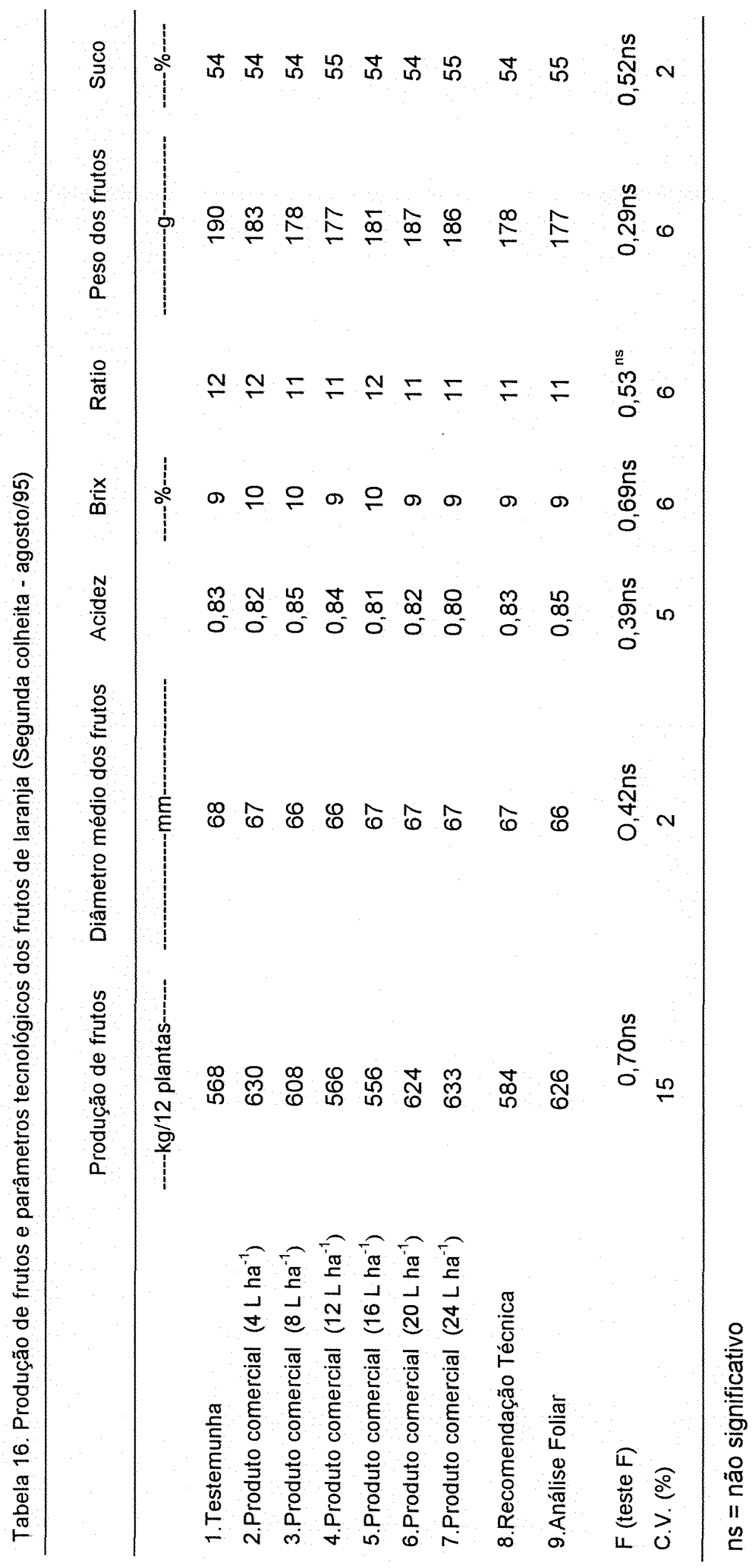




\subsection{Experimento II}

\subsubsection{Resultados das Análises de Folhas}

Na Tabela 17 estão apresentados os dados referentes a análise foliar para os micronutrientes ( $\mathrm{B}, \mathrm{Cu}, \mathrm{Fe}, \mathrm{Mn}$ e $\mathrm{Zn}$ ). Os dados mostram diferenças entre as médias dos teores foliares de micronutrientes. Os teores de manganês e o zinco tiveram uma tendência geral de crescer até os 8 primeiros anos e a seguir decrescer conforme aumenta a idade do pomar, provavelmente porque nos pomares mais velhos a freqüência das pulverizações foliares são menores (Comunicação pessoal do gerente da propriedade). Observando-se os dados verifica-se que os teores dos micronutrientes estão dentro da faixa considerado adequada (Grupo Paulista de Adubação e Calagem para Citros, 1994), com exceções, dos teores foliares de cobre nos pomares Pera com 7 anos e Natal com 11 e 13 anos. $O$ pomar de Pera com 20 anos foi o que apresentou o maior teor de cobre, porque havia recebido dias antes da coleta de folhas uma pulverização com fungicida cúprico. Os teores muito elevados, como no caso do boro para laranja Natal 13 anos $\left(90 \mathrm{mg} \mathrm{dm}^{-3}\right)$ e zinco para laranja Pera 8 anos $\left(186 \mathrm{mg} \mathrm{dm}^{-3}\right)$, são devidos ao fato de que estes talhões receberam pulverizações dias antes da coleta de folhas. As diferenças entre os teores de micronutrientes nas folhas foram provavelmente provocadas pela época das aplicações foliares, ou seja os maiores teores são para os talhões que receberam pulverizações poucos dias antes da coleta das folhas, com exceção do ferro, que não entra no esquema de pulverizações foliares. 


\subsubsection{Resultados da Análise do Solo para Micronutrientes}

\subsubsection{Boro}

$\mathrm{Na}$ Tabela 18 estão os teores de boro no solo coletado em pomares de diferentes idades. Os teores de boro são muito baixos para todos os pomares avaliados. Em relação a idade das plantas verifica-se que os teores de boro pouco variaram, sendo que isto aconteceu nas 3 posições de amostragem. Com relação a posição de coleta há uma tendência de se ter concentrações maiores de boro nas amostras coletadas na projeção da copa e próximo ao colo da planta, pois em todos pomares estes são maiores do que os teores obtidos nas amostras da entrelinha, exceção a testemunha (Figura 1). Portanto a hipótese de que há um acúmulo de boro no solo com o aumento da idade do pomar é verdadeira, mas a influência é muito pequena, insuficiente para elevar substancialmente o seu teor no solo. Isto talvez seja explicado pelo fato de que a quantidade de boro aplicada anualmente via foliar é muito pequena e o boro pode ser facilmente lixiviado, principalmente em solos com reação próximo a neutralidade, pH entre 5,5 a 7,0 (Malavolta, 1980). 
Tabela 17. Resultados da análise química de folhas de laranjeira para micronutrientes

\begin{tabular}{|c|c|c|c|c|c|}
\hline Tratamentos & $B$ & $M n$ & $\mathrm{Zn}$ & $\mathrm{Cu}$ & $\mathrm{Fe}$ \\
\hline & $\ldots$ & $\ldots$ & $\mathrm{dm}^{-3}$ & & 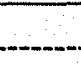 \\
\hline $\begin{array}{l}\text { Pera três anos } \\
\text { Pera quatro anos } \\
\text { Pera seis anos } \\
\text { Pera sete anos } \\
\text { Pera oito anos }\end{array}$ & $\begin{array}{l}50 \\
56 \\
63 \\
67 \\
60\end{array}$ & $\begin{array}{l}32 \\
62 \\
71 \\
75 \\
77\end{array}$ & $\begin{array}{l}134 \\
191 \\
119 \\
154 \\
186\end{array}$ & $\begin{array}{l}20 \\
11 \\
16 \\
4 \\
13\end{array}$ & $\begin{array}{l}154 \\
134 \\
186 \\
178 \\
160\end{array}$ \\
\hline $\begin{array}{l}\text { Natal onze anos } \\
\text { Natal treze anos }\end{array}$ & $\begin{array}{l}69 \\
90\end{array}$ & $\begin{array}{l}60 \\
61\end{array}$ & $\begin{array}{l}115 \\
40\end{array}$ & $\begin{array}{l}4 \\
4\end{array}$ & $\begin{array}{l}146 \\
172\end{array}$ \\
\hline $\begin{array}{l}\text { Pera catorze anos } \\
\text { Pera vinte anos }\end{array}$ & $\begin{array}{l}70 \\
68\end{array}$ & $\begin{array}{l}50 \\
22\end{array}$ & $\begin{array}{l}63 \\
23\end{array}$ & $\begin{array}{l}18 \\
36\end{array}$ & $\begin{array}{l}140 \\
139\end{array}$ \\
\hline
\end{tabular}

Tabela 18. Teores médios de boro no solo

\begin{tabular}{lccc}
\multicolumn{1}{c}{ Idade } & A & B & C \\
\hline & & Posição da Coleta- & \\
\hline Testemunha & 0,1 & 0,1 & 0,1 \\
Pera três anos & 0,1 & 0,1 & 0,1 \\
Pera quatro anos & 0,2 & 0,2 & 0,1 \\
Pera seis anos & 0,3 & 0,3 & 0,2 \\
Pera sete anos & 0,2 & 0,3 & 0,1 \\
Pera oito anos & 0,2 & 0,3 & 0,2 \\
Natal onze anos & 0,2 & 0,2 & 0,1 \\
Natal treze anos & 0,2 & 0,3 & 0,1 \\
Pera catorze anos & 0,1 & 0,2 & 0,1 \\
Pera vinte anos & 0,2 & 0,2 & 0,2 \\
Média & 0,2 & 0,2 & 0,1 \\
\hline
\end{tabular}

$A=$ Próximo ao colo da planta

$B=$ Na projeçào da copa

$\mathrm{C}=\mathrm{Na}$ entrelinha das plantas 


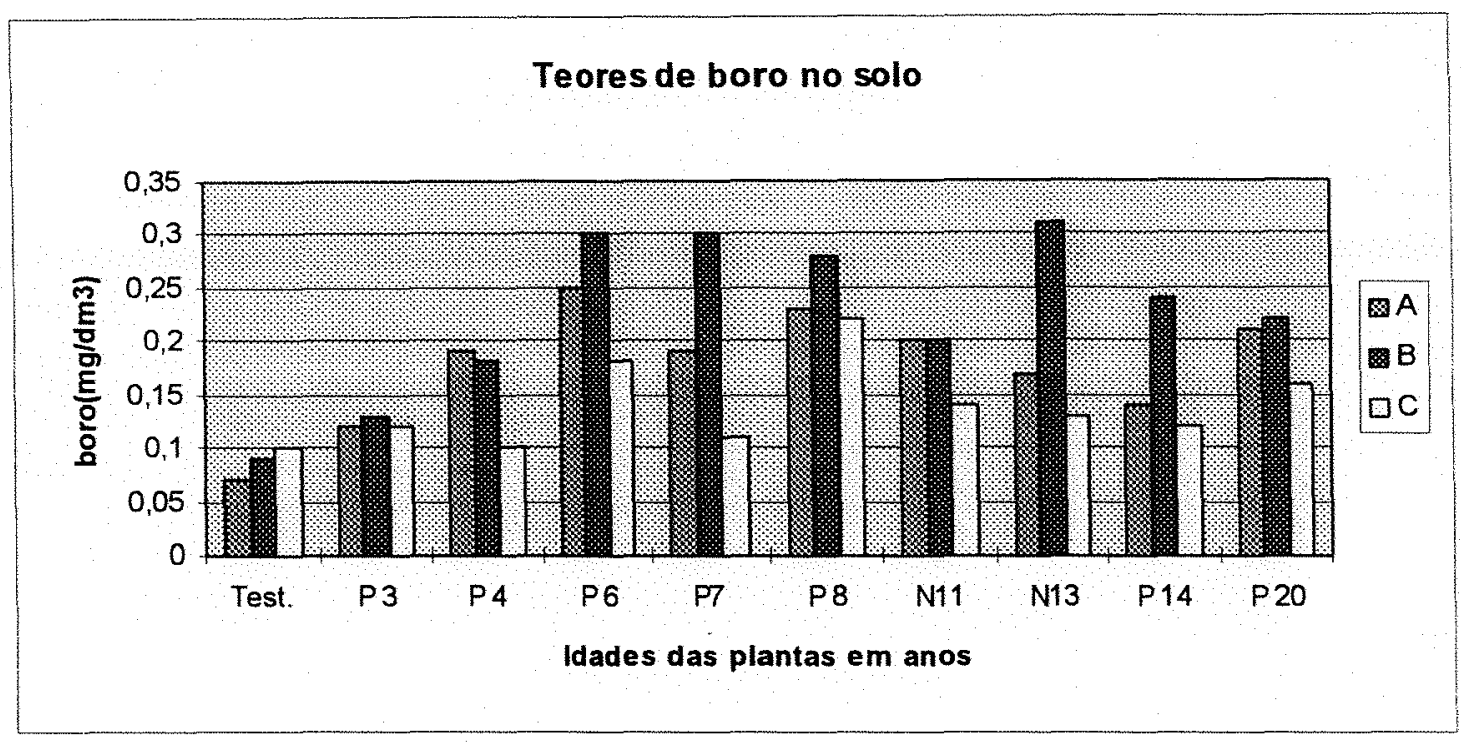

Figura 1. Teores de Boro no solo

A - Próximo ao colo da planta.

B - Na Projeção da Copa.

C - Na entrelinha das plantas

$P$ - Pera

$N$ - Natal

\subsubsection{Zinco}

Na Tabela 19 e na Figura 2 estão apresentados e visualizados os dados referentes aos teores de zinco no solo. Verifica-se que o menor teor de zinco foi para a área testemunha.

Os teores baixos de zinco da área testemunha mostra que o solo é naturalmente muito pobre em zinco, e que a adubação foliar pode estar contribuindo para elevar os teores de zinco no solo, a níveis altos, o que pode ser visto pelas médias na Tabela 19.

O maior teor de zinco encontrado foi para o pomar de laranja Pera com 3 anos, nas posições próximo ao colo da planta e projeção da copa. Em relação a idade das plantas, verifica-se que os pomares de Pera com 4,6 e 8 anos, apresentaram teores semelhantes entre si, mas apresentando teores de 
zinco bem maiores que as demais idades, com exceção do pomar de Pera com 3 anos. Isto provavelmente deve-se ao fato de que nestes talhões a fazenda ainda faz duas aplicações foliares de produtos contendo $\mathrm{B}, \mathrm{Mn}$ e $\mathrm{Zn}$ por ano, com a finalidade de prevenir problemas de deficiência.

Tabela 19. Teores de zinco no solo

\begin{tabular}{|c|c|c|c|}
\hline \multirow[t]{2}{*}{ Idade } & $A$ & $B$ & $c$ \\
\hline & 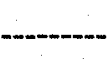 & $\mathrm{gg} \mathrm{dm}$ & \\
\hline $\begin{array}{l}\text { Testemunha } \\
\text { Pera três anos } \\
\text { Pera quatro anos } \\
\text { Pera seis anos } \\
\text { Pera sete anos } \\
\text { Pera oito anos }\end{array}$ & $\begin{array}{r}0,2 \\
55,6 \\
19,4 \\
13,6 \\
6,6 \\
15,4\end{array}$ & $\begin{array}{r}0,2 \\
29,2 \\
9,9 \\
12,2 \\
5,0 \\
9,6\end{array}$ & $\begin{array}{r}0,3 \\
14,6 \\
3,1 \\
3,1 \\
1,7 \\
6,4\end{array}$ \\
\hline $\begin{array}{l}\text { Natal onze anos } \\
\text { Natal treze anos }\end{array}$ & $\begin{array}{l}7,8 \\
6,2\end{array}$ & $\begin{array}{l}6,4 \\
7,6\end{array}$ & $\begin{array}{l}2,2 \\
3,8\end{array}$ \\
\hline $\begin{array}{l}\text { Pera catorze anos } \\
\text { Pera vinte anos }\end{array}$ & $\begin{array}{l}5,8 \\
4,7\end{array}$ & $\begin{array}{l}5,5 \\
2,6\end{array}$ & $\begin{array}{l}2,3 \\
1,5\end{array}$ \\
\hline Média & 15,0 & 8,8 & 3,9 \\
\hline
\end{tabular}

$A=$ Próximo ao colo da planta

$B=$ Na projeçào da copa

$C=$ Na entrelinha das plantas 


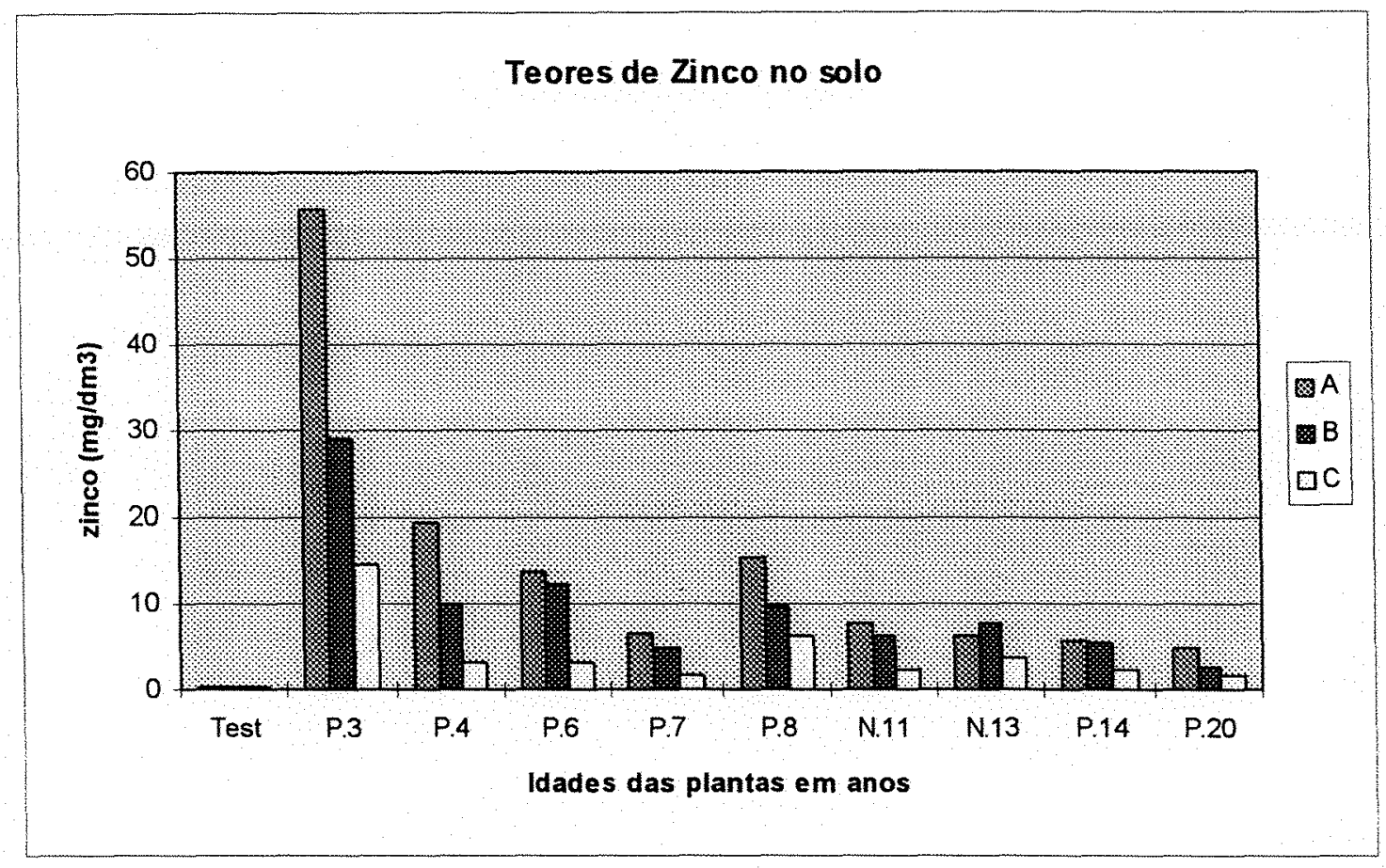

Figura 2. Teores de Zinco no solo

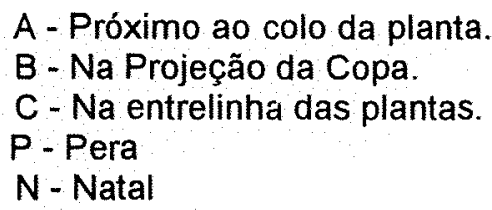

Com relação a posição de coleta observa-se em todos os tratamentos que as posições próximo ao colo da planta e projeção da copa apresentaram maiores teores de zinco do que na entrelinha, ou seja ,os teores de zinco na entrelinha são bem menores do que nas outras 2 posições. Os dados mostram que no caso do zinco as adubações foliares e a intensidade das aplicações estão interferindo nos teores de zinco no solo.

Os altos teores de zinco no solo apresentaram uma estreita relação com os teores de zinco na planta. Verifica-se que há uma tendência dos maiores teores no solo refletirem os maiores teores nas plantas. 


\subsubsection{Manganês}

Na Tabela 20 e na Figura 3 estão os dados referente aos teores de manganês no solo. De forma geral, os teores de manganês do solo eram altos (Grupo Paulista de Adubação e Calagem para Citros, 1994), pois estavam acima de $5 \mathrm{mg} \mathrm{dm}^{-3}$. Os pomares que apresentaram teores médios $\left(1,5\right.$ a $\left.5,0 \mathrm{mg} \mathrm{dm}^{-3}\right)$ Natal 11 anos, Pera 14 e 20 anos e para os demais tratamentos os teores apresentaram valores bastante dispersos, variando de 6 a $30 \mathrm{mg} \mathrm{dm}^{-3}$. Os pomares que apresentaram os maiores teores de manganês foram a Pera 3 e 7 anos e Natal 13 anos. Com relação a posição de coleta de amostras de solo verifica-se uma pequena superioridade nos teores de manganês nas posições de coleta projeção da copa e perto do colo da planta em relação a entrelinha. Isto só não aconteceu nos pomares com Pera 8 e 20 anos. Verifica-se que a diferença nos teores de manganês nas amostras coletadas próximo ao colo da planta e na projeção da copa em relação a entrelinha é muito pequena, bem diferente do caso do zinco e cobre. Para os teores de manganês fica muito difícil dizer que as diferenças entre as posições de coleta é em função das aplicações foliares e escorrimento de calda para o solo.

Para o manganês a hipótese é descartada, ou seja a quantidade aplicada nas adubações foliares e que escorrem para o solo é insuficiente para aumentar o teor no solo. Outro fator que pode determinar a quantidade de manganês no solo é a reação do solo. Como o pH do solo nos talões é elevado (Tabela 10) a disponibilidade do manganês no solo é baixa, devido as reações de fixação de manganês que normalmente ocorrem em valores de $\mathrm{pH}$ acima de 5,0. 
Tabela 20. Teores de manganês no solo

\begin{tabular}{lrrr}
\multicolumn{1}{c}{ Idade } & A & B & Cosição da Coleta- \\
\hline & & & \\
& & & \\
Testemunha & 5,1 & 5,3 & 5,1 \\
Pera três anos & 22,6 & 15,2 & 11,0 \\
Pera quatro anos & 13,5 & 8,8 & 6,5 \\
Pera seis anos & 6,7 & 11,7 & 5,8 \\
Pera sete anos & 20,2 & 30,0 & 22,4 \\
Pera oito anos & 14,8 & 14,0 & 15,2 \\
Natal onze anos & 4,2 & 3,0 & 3,3 \\
Natal treze anos & 27,0 & 24,2 & 23,6 \\
Pera catorze anos & 3,8 & 3,1 & 3,6 \\
Pera vinte anos & 5,4 & 6,8 & 8,2 \\
& & 12,2 & 10,5 \\
Média & 12,3 & & \\
\hline
\end{tabular}

$A=$ Próximo ao colo da planta

$\mathrm{B}=$ Na projeçào da copa

$\mathrm{C}=\mathrm{Na}$ entrelinha das plantas

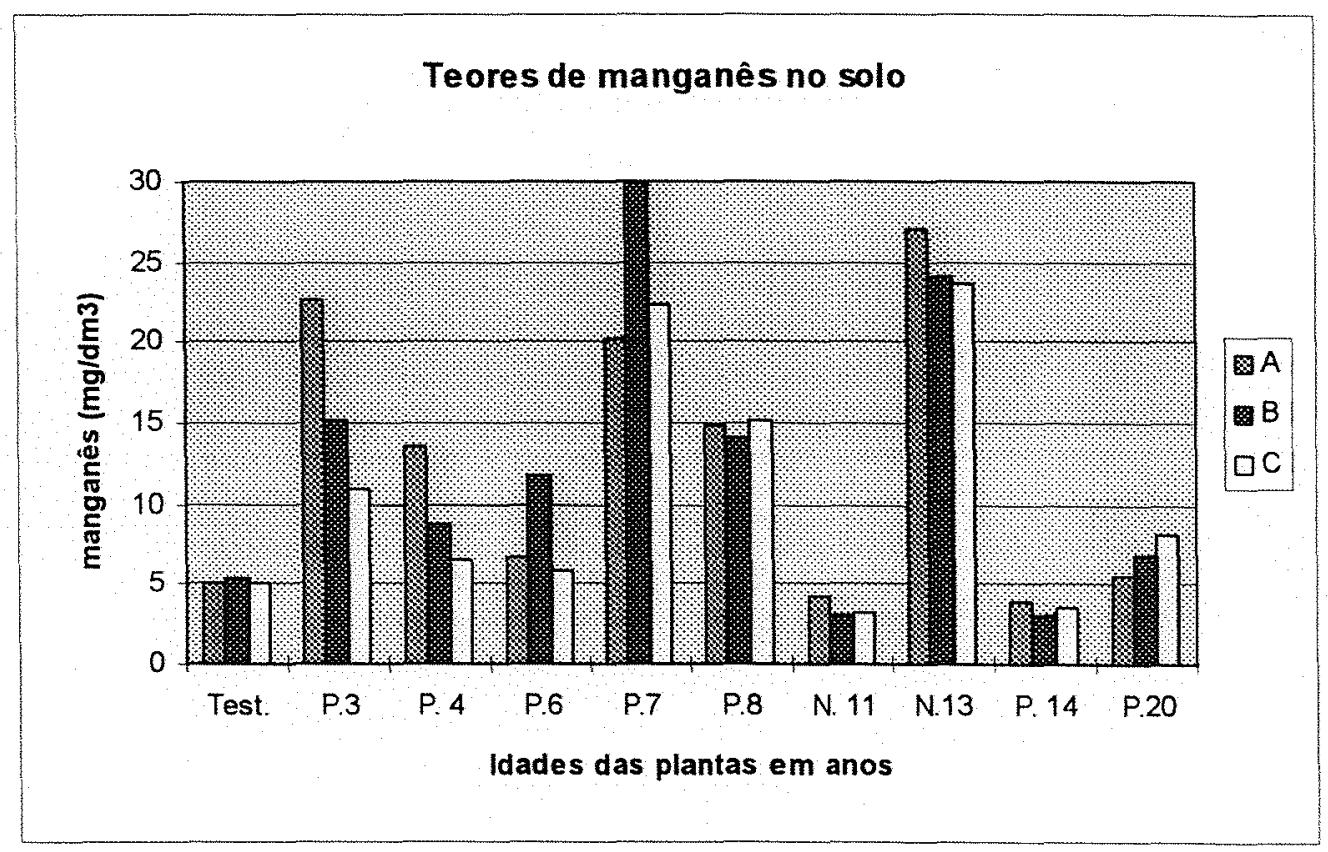

Figura 3. Teores de Manganês no solo.

A - Próximo ao colo da planta.

B - Na Projeção da Copa.

C - Na entrelinha das plantas

P-Pera

$N$ - Natal 


\subsubsection{Cobre}

Para o cobre Tabela 21 e Figura 4 os dados são muitos divergentes.

Os teores de cobre da área testemunha são muito baixos (Grupo Paulista de Adubação e Calagem para Citros, 1994). Os maiores teores foram encontrados nas amostras de solo nos pomares com Pera 8 anos e Pera 20 anos. As diferenças nos teores de cobre são provavelmente devido as aplicações de fungicida cúprico. Os dados mostram que os teores de cobre decrescem da posição próximo ao colo da planta para a entrelinha, confirmando também a influência da aplicações foliares nos teores de cobre em função da posição de coleta.

Tabela 21. Teores de cobre no solo

\begin{tabular}{|c|c|c|c|}
\hline \multirow{3}{*}{ Idade } & \multirow[b]{2}{*}{ A } & \multirow{2}{*}{$\begin{array}{c}0 \mathrm{da} \\
\mathrm{B}\end{array}$} & \multirow[b]{2}{*}{$\mathrm{C}$} \\
\hline & & & \\
\hline & \multicolumn{3}{|c|}{$\mathrm{mg} \mathrm{dm}^{-3}$} \\
\hline Testemunha & 0,6 & 0,6 & 0,6 \\
\hline Pera três anos & 11,0 & 7,8 & 6,6 \\
\hline Pera quatro anos & 10,8 & 9,2 & 6,1 \\
\hline Pera seis anos & 5,7 & 6,1 & 6,7 \\
\hline Pera sete anos & 5,4 & 5,2 & 4,7 \\
\hline Pera oito anos & 12,5 & 9,2 & 8,1 \\
\hline Natal onze anos & 5,1 & 2,2 & 1,8 \\
\hline Natal treze anos & 9,6 & 6,8 & 5,5 \\
\hline Pera catorze anos & 11,4 & 5,1 & 2,7 \\
\hline Pera vinte anos & 14,8 & 5,8 & 4,6 \\
\hline Média & 8,7 & 5,8 & 4,7 \\
\hline
\end{tabular}

$A=$ Próximo ao colo da planta

$B=$ Na projeçào da copa

$\mathrm{C}=\mathrm{Na}$ entrelinha das plantas 


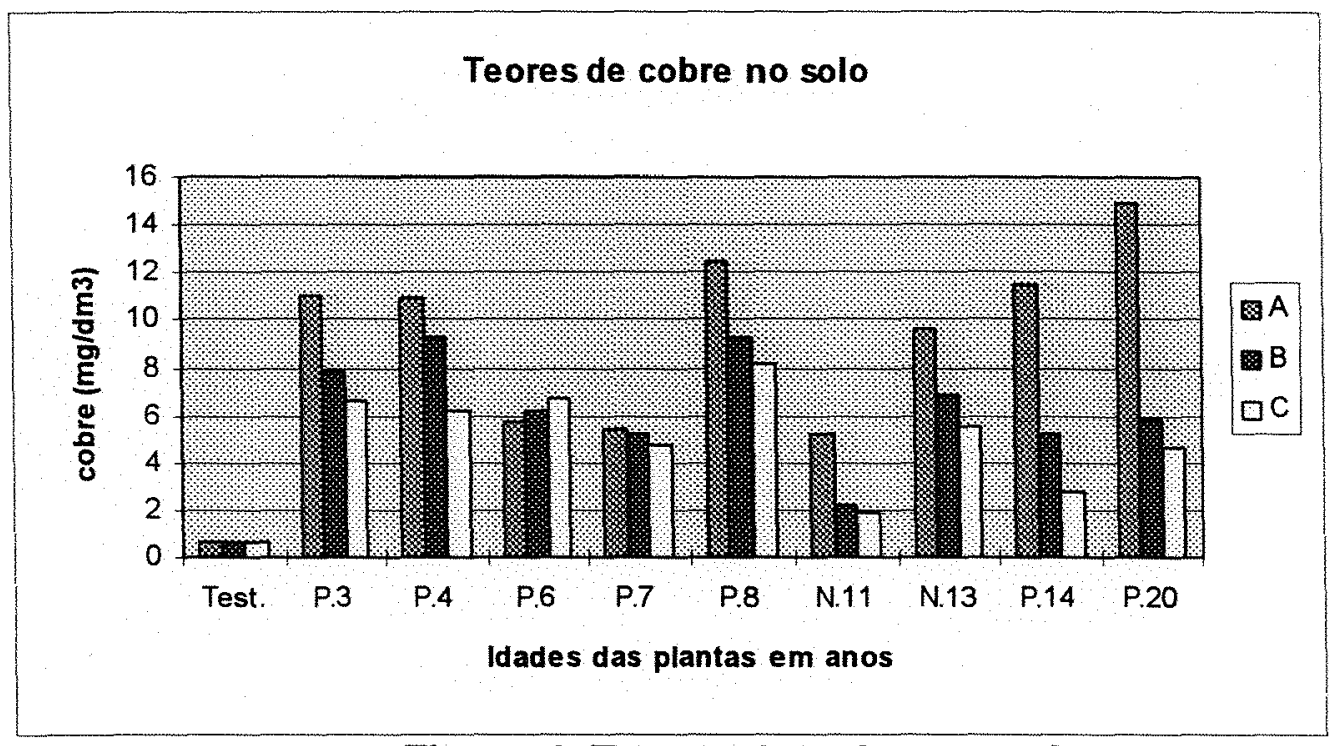

Figura 4. Teores de cobre no solo

A - Próximo ao colo da planta

B - Na projeção da copa

C- Na entrelinha das plantas

P. Pera

$N$ - Natal

\subsubsection{Ferro}

Os dados da Tabela 22 e da Figura 4 mostram que os maiores teores de ferro foram determinados na área testemunha. Os maiores teores de ferro da área testemunha, provavelmente estão associados ao $\mathrm{pH}$ do solo, que nesta área era menor em relação as áreas cultivadas (Tabela 10). É sabido que em solo com pH baixo (menor que 4,5 ), há maior disponibilidade de ferro. A calagem diminui a disponibilidade de ferro no solo, devido as reações de fixação que normalmente ocorrem em solos com pH próximo a neutralidade $(5,0-7,0)$. 
Tabela 22. Teores de ferro no solo

\begin{tabular}{lrrr}
\hline \multicolumn{1}{c}{ Idade } & A & Posição da Coleta- & \\
& & & \\
& & & \\
\hline & 105,0 & 113,4 & dm$^{-3}$ \\
Testemunha & 39,0 & 26,4 & 111,8 \\
Pera três anos & 37,8 & 30,8 & 21,0 \\
Pera quatro anos & 23,0 & 33,2 & 18,4 \\
Pera seis anos & 5,1 & 6,7 & 20,2 \\
Pera sete anos & 19,2 & 21,2 & 5,4 \\
Pera oito anos & 15,3 & 15,2 & 17,5 \\
Natal onze anos & 7,5 & 7,4 & 17,7 \\
Natal treze anos & 14,9 & 12,5 & 7,2 \\
Pera catorze anos & 7,9 & 6,9 & 7,0 \\
Pera vinte anos & & 27,4 & 4,4 \\
Média & 27,4 & & 23,1 \\
\hline
\end{tabular}

$A=$ Próximo ao colo da planta

$B=$ Na projeçào da copa

$C=$ Na entrelinha das plantas

Os altos teores de ferro da área testemunha indicam que o solo é rico em ferro, e que a calagem deve ter diminuído a quantidade extraida pelo DPTA, provocando uma diferença muito grande entre os teores de ferro da testemunha para as áreas cultivadas. Nos pomares em que o solo foi corrigido (pH acima de 5.5), os teores de ferro são bem menores. Em relação a posição de coleta verifica-se que as diferenças entre os teores de ferro das amostras coletadas próximo ao colo da planta e na entrelinha são muito pequenas. Isto era de se esperar, pois o ferro não entra na composição das adubações foliares para laranja, portanto não tem como acumular no solo em função das pulverizações. 


\subsection{Discussão Geral dos Micronutrientes}

Analisando os resultados dos teores no solo de boro, manganês e zinco que são aplicados na adubação foliar e cobre aplicado como defensivo, verifica-se que há uma tendência de aumento dos teores destes micronutrientes no solo, que se torna mais evidente pela comparação dos teores das amostras coletadas nas diferentes posições. A adubação foliar portanto, além de fornecer nutrientes para as plantas através das folhas, também acrescenta nutrientes no solo através da solução pulverizada que não é retida pela laranjeira. Os quais podem ser absorvidos pelas plantas, através das raízes. Embora deve-se ressaltar que a quantidade de micronutrientes no solo proveniente da adubação foliar é muito pequena para o boro e manganês e é ponderável para o caso do zinco. Outro detalhe importante é o comportamento dos micronutrientes no solo, porque o simples acúmulo no solo através do escorrimento da calda das adutações foliares não necessariamente implica no aumento da disponibilidade destes para as plantas. 


\section{CONCLUSÕES}

\subsection{Experimento 1}

1. A aplicação de micronutrientes via foliar elevou os teores destes nas folhas;

2. Os teores de boro, zinco e manganês apresentaram diferenças estatísticas entre as doses do produto comercial e em relação ao tratamento testemunha;

3. Não houve efeito da adubação foliar no teor foliar de macronutrientes nos dois anos de estudos;

4. A aplicação dos micronutrientes não tiveram influência na produção de frutos, diâmetro médio dos frutos e parâmetros tecnológicos, nos dois anos de estudos.

\subsection{Experimento 2}

a- $A$ adubação foliar interfere muito pouco nos teores de micronutrientes no solo, em função da idade do pomar;

b- Para todos os micronutrientes estudados $(\mathrm{B}, \mathrm{Mn}, \mathrm{Cu}, \mathrm{Fe}$ e $\mathrm{Zn}$ ), houve uma tendência de aumento dos teores no solo, para as posições, projeção da copa e próximo ao colo da planta, em relação a entrelinha. 


\section{REFERENCIAS BIBLIOGRÁFICAS}

ASHAMED, H.D. The absorption of amino acid chelates by plant cells. In: ASHAMED, H.D.; ASHMEAD, H.H.; MILLER; G.W.; ed. et al. Foliar feedings of plants with amino acid chelates. Park Ridge : Noyes Publications, 1986. p. 219-35.

BARNARD, R.O.; FOLSCHER,W.J.; OBERHOLZER, P.C.J. The uptake of Zn, $\mathrm{Mn}, \mathrm{Cu}$ and B from spray mistures by navel oranges leaves. Plant and Soil, The Hague, v.39, p.429-32, 1973.

BEN DAVID, M.D. Mineral nutrition an irrigation in citrus crops. Ciba Geigy Agrochemi-cals : Basle, 1975. p. 14-20.

BOARETTO, A.E.; SALVADOR, J.A.; COSTA, T.R.R. Aplicação foliar de aminoácidos na cultura do feijoeiro. Relatório de pesquisa. Piracicaba : Centro de Energia Nuclear na Agricultura, 1990, 11p. 
CABRITA, J.R.M. Aplicação de boro, manganês e zinco, via solo e foliar em citros, Jaboticabal, 1993. 47p. Dissertação (Mestrado na área de Concentração, Produção Vegetal). Faculdade de Ciências Agrárias e Veterinária, Campus de Jaboticabal, UNESP.

CAETANO, A..A.; MOREIRA, C.S.; DE NEGRI, J. D. ; FIGUEIREDO, J. O.; TEÓFILO SOBRINHO, J. ; HIROCE, J. Estudo da eficiência de várias fontes dos micronutrientes $\mathrm{Zn}, \mathrm{Mn}$ e $\mathrm{B}$, aplicados em pulverizações na laranjeira Valência Citrus sinensis (L) Osbeck. Informações Agronômicas, v.27, p. 139$145,1982$.

CAMARGO, P.N.; SILVA, O. Micronutrientes. In: Manual de adubação foliar. São Paulo : Herba, 1975. p. 136-149.

CAMP, A.F; FUDGE, B.R. Some symptons of citrus malnutrition in Flórida. Gainesville : Bulletin Agricultural Experiment Station, 1939. p.55-335.

CASTRO, A.M.C. Adubação foliar e tratamento de sementes de feijoeiro (Phaseolus vulgaris, L.) com nutrientes, vitamina Bl e metionina. Botucatu, 1991. 97p. (Mestrado em Ciências Agronômicas). Faculdade de Ciências Agronômicas. 
CHAPMAN, H.D. Zinc. In: CHAPMAN, H.D., ed. Diagnostic criteria for plants and soils. Universtiy of Califomia/Division of Agricultural Sciences, 1966. Cap.33, p. 484-499.

CRUZ, M.C.P. \& FERREIRA, E.M. Seleção de métodos para avaliação do boro disponivel em solos. Pesquisa Agropecuária Brasileira, Brasilia, v. 19:14571464, 1984.

DECHEN, A.R.; NEVES, C.S.V.J. Aplicação foliar de nutrientes. Laranja, Cordeirópolis, v.9, p.66-92, 1988.

DESZYCK, E.J.; SITES, J.W. The effect of borox and lead arsenate spray on the total acid and maturity of marsh grapefruit. Proceeding of the Florida State Horticultural Society, v.66, p.62-65, 1954.

DUCATTI, R.P. Influência da aplicação de micronutrientes via solo e foliar na laranjeira pera. Jaboticabal, 1991.55p. (Monografia apresentada à Faculdade de Ciências Agrárias e Veterinária, UNESP, Campus de Jaboticabal, para obtenção do título de Bacharel em Agronomia).

EL-FOULY, M.M.; FIRGANY, A.H.; FAWZI, A.F.A. et al. The effect of amino acid chelates on yield of different crops in Egypt. In: INTERNATIONAL CITRUS CONGRESS, 6., Tel Avive, 1988. Citriculture. Rehoot, Balabean Publ., 1988. p.6-1. 
FIGUEIREDO, J.O. Variedades copas de valor comercial In: RODRIGUES, O.; VIÉGAS, J.; POMPEU Jr., J. Citricultura brasileira. Campinas Fundação Cargill, 1991, p.228-264

FRANKE, W. The basis of foliar absorption of fertilizers with special regard to the mecanisms. In: ALEXANDERA, ed. Foliar fertilization. Proc. Lat. Int. Symp. on foliar fertilization. Dordrecht, Martinus Nijhoff Flublishers, 1986. p. 17-25.

GEUS, J. G. Fruit crops-citros. In: Fertilizer guide for the tropics and subtropcs. Centre D’Etude de Lázote, Bleichenweg, Zurich, p. 590-616, 1973.

GRUPO PAULISTA DE ADUBAÇÃO E CALAGEM PARA CITROS. Recomendações de adubação e calagem para citros no Estado de São Paulo. Laranja, Cordeirópolis, v.43, n.9, p.1-15, 1994.

HAQUE, M.Z.; KOBAYASM, M.; FUJI, K. The incorporations of amino acids and nucleic acid bases into the seedling, reproductive stage and young ear portion of rice plant. Plant and Soil, Dordrecht, v.34, p.17-24, 1971.

HILGEMAN, R.H.; SHARPLES, G.C. Manganese deficiency in grapefruit in Arizona. Israel Journal Agriculture Research, v.18, n.4, p.187-191, 1968. 
HSU, H.H. The absorption and distribuitions of metalosates from foliar fertilization. In: ASHAMED, H.D.; ASHAMED, H.H.; MIILLER, G.W. et al., ed. Foliar feedings of plants with amino acid chelates. Park Ridge : Noyes Publications, 1986a. p.236-254.

HSU, H.H. Chelates in plant nutrition. In: ASHAMED, H.D.; ASHAMED, H.H.; MLLLER, G.W. et al., ed. Foliar feeding of plants with amino acid chelates. Park Ridge : Noyes Publications, 1986b. p.209-218.

INSTITUTO INTERAMERICANO DE LA POTASSA. La nutricion mineral de los agrios. Berna : Instituto Internacional de la Potassa, 1958. p.3446.

KOTUR, S.C. The comparison of zinc oxide, unneutralized and neutralized zinc sulphate as foliar sprys in Coorg mandarin. Indian Journal of Agriculture Sciences, New Delhi, v.5, n.3, p.186-188, 1984.

LABANAUSKAS, C.K; JONES, W.W.; EMBLETON, T.W. Low-residue micronutrient nutri-tional sprays for citrus. In: INTERNATIONAL SIMPOSIUM, 1. 1969. Proceedings 1969 , v.3 p.1535-42.

LABANAUSKAS, C.K.; PUFFER, R.E. Effects of foliar aplications of manganese, zinc, and urea on Valencia orange yield and foliage composition. Genebra: Proceedings American Society for Horticultural Science, 1964. v.84, p. 154-164. 
LINDSAY, W.L.; NORWELL, W.A. Development of a DTPA soil test for zinc, iron, manganese and copper. Soil Sci. Soc. Am. J., v.42, p.421-428, 1978.

MALAVOLTA, E. Elementos de nutrição mineral de plantas. São Paulo : Ceres, 1980. 251p.

MALAVOLTA, E.; HAAG, H.P.; MELLO,.F.A.F. et al. Nutrição mineral e adubação das plantas cítricas. In: MALAVOLTA, E. Nutrição mineral e adubação das plantas cultivadas. São Paulo : Ceres, 1974. Cap.6, p.293-324.

MALAVOLTA, E.; VITTI, G.C.; DE OLIVEIRA, S.A.; Avaliação do estado nutricional das plantas: Princípios e aplicações.Piracicaba. Associação Brasileira para Pesquisa da Potassa e do Fosfato, 1989. 201p.

MELLO, W.J.; FORNASIERI FILHO, D.; VITTI, G.C. Efeito de um ativador biológico à base de cisteína sobre a cultura do milho (Zea mays, L.). Revista de Agricultura, Piracicaba, v.58, n.3, p.159-167, 1983.

MACHADO, R. D. Influência da aplicação dos micronutrientes $B$. Mn, Zn via solo e foliar na laranjeira pera, anos 1991/92 e 1992/93. Jaboticabal, 1991. 57p. (Monografia apresentada à Faculdade de Ciências Agrárias e Veterinária, UNESP, Campus de Jaboticabal, para obtenção do título de Bacharel em Agronomia). 
MENDES, L.D.T. A maturação dos frutos cítricos. São Paulo: Departamento de Fomento da Produção Vegetal, 1936. 9p. (Circular 3).

MILLER, G.W.W.; WARNICK, K. Koliar aplications of micronutrients in correcting deficiencies in oats. In: ASHMEAD, H.D.; ASHMEAD, H.H.; MILLER, G.W. et al., ed. Foliar feeding of plants with amimo acid chelates. Park Ridge : Noyes Publications, 1986. p.300-320.

MILLER, G.W.; HSU, H.H., ed. Foliar feeding of plants with amino acid chelates. Park Ridge : Noyes Publications, 1986. p.281-288.

MORI, S.M.; NISHIZAWA, N. Nitrogen absorption by plant root from the cultura medium where organic and inorganic nitrogen coexist. $R$. Which nitrogen is preferentially absorved among, $\left[\mathrm{U}-{ }^{14} \mathrm{C}\right]$ Glu-NH,$\left[2.3-{ }^{3} \mathrm{H}\right] \mathrm{Arg}$. and $\mathrm{Na}^{15} \mathrm{NO}_{3}$. Soil Science and Plant Nutrition, v.25, n.1, p.51-88, 1979.

OSAKI, F. Calagem \& Adubação. Campinas: Instituto Campineiro de Ensino Agrícola, 1991. 503p.

PARKER, E.R. \& SOUTHWICK, R.W. Manganes deficiency in citms. Proceedings of the American Society for Horticulture Science, v.39, p.51$58,1941$. 
REITZ, H.J. Manganese deficiency. In: PRATT, R.M. ed. Florida guide to citrus insums: diseases and nutritional disordens in calor. Gainesville : Agricultural Experiment Station, 1958. p.48-49.

RAZETO, B.M.; SALAS, A. Magnesium and zinc sprays on orange tree (Citrus sinensis L.). In: INTERNATIONAL SYMPOSIUM ON FOLIAR FERTILIZATION, 1., Dordrechet, 1985. Proceedings, Dordrecht : us Nijhoff, 1986. p. 255-270.

RAZETO, B. M. ; LONGUEIRA, J. M. ; ROJAS, S. Z.; REGINATO, G. M. Correccion de las deficiencias de manganeso y cinc. Agricultura tecnica, v. 48, n. 4, p. $347-352,1988$

RODRIGUES, 0. Aspectos principais da nutrição e carência minerais do citros. In: Ciclo de palestras e debates sobre citricultura. Cordeirópolis : Estação Experimental de Limeira, 1974. p. 80-90.

SALIBE, A. A. Cultura dos citros. Recife: SUDENE/UFRPe, 1974. p.80-90.

SHAZLY, S.A. The effect of amino acid chelated in mineral correcting mineral deficiencies and increasing fruit production in trees in Egypt. In: ASHMEAD, H.D.; ASHMEAD, H.H.; MILLER, G.W. ed. et al. Foliar feeding of plants with amimo acid chelates. Park Ridge: Noyes Publications, 1986. p. 289299. 
STOLLER, J. Adubação foliar em citrus. Laranja, Cordeirópolis, v. 10, n.2, p.545$554,1989$.

TRANI, P.E. ; HIROCE, R. ; BATAGLIA, O. C. Análise foliar, amostragem e interpretação. Campinas. Fundação cargil, 1983, 31p.

VITTI, G. C. Nutrição e crescimento das plantas cítricas. In: SEMINÁRIO INTERNACIONAL DE FISIOLOGIA DE CITROS, 1992. Anais. . Bebedouro, p.139158. 